\title{
Interannual variability of the early and late-rainy seasons in the Caribbean
}

\author{
Carlos Martinez ${ }^{1,2,3} \cdot$ Yochanan Kushnir $^{2} \cdot$ Lisa Goddard $^{3} \cdot$ Mingfang Ting $^{2}$
}

Received: 12 February 2020 / Accepted: 15 June 2020 / Published online: 19 June 2020

(c) The Author(s) 2020

\begin{abstract}
The Caribbean seasonal rainfall cycle and its characteristics are heavily relied upon by the region's inhabitants for their socioeconomic needs; the prediction of its variability would be valuable to society. An important way to understand the predictability of the Caribbean rainfall cycle is to study its interannual variability. Previous studies vary as to how and what large-scale climate driver(s) affect the interannual variability of rainfall and its associated dynamical mechanisms in the Caribbean. To address this, this study investigates wet and dry Caribbean early-rainy seasons (ERS; mid-April to mid-June) and late-rainy seasons (LRS; late August to mid-November) by conducting the following: (1) a spatial composite of rainfall from 34 Caribbean rainfall stations using daily data; and, (2) spatial composites of sea-surface temperature, sea-level pressure, and mean flow moisture convergence and transports. The ERS and LRS are impacted in distinctly different ways by two different, and largely independent, dominant large-scale phenomena: the North Atlantic Oscillation (NAO) and the El Niño-Southern Oscillation (ENSO), respectively. Dry ERS years are associated with a persistent dipole of cold and warm SSTs over the Caribbean Sea and Gulf of Mexico, respectively, that were caused by a preceding positive NAO state. This setting involves a wind-evaporation-SST (WES) feedback expressed in enhanced trade winds and consequently, moisture transport divergence over all of the Caribbean, except in portions of the NW Caribbean in May. A contribution from the preceding winter cold ENSO event is also discernible during dry ERS years. Dry LRS years are due to the summertime onset of an El Niño event, developing an inter-basin SLP pattern that fluxes moisture out of the Caribbean, except in portions of the NW Caribbean in November. Both large-scale climate drivers would have the opposite effect during their opposite phases leading to wet years for both seasons. The two rainy seasons are independent because the main drivers of their variability are independent. This has implications for prediction.
\end{abstract}

\section{Introduction}

Understanding Caribbean mean rainfall and its variability is crucial for enhancing predictability of the rainfall cycle and understanding future projections of the rainfall cycle, given the regions' high-vulnerability to climate variability and change (Taylor et al. 2012). How stakeholders in the Caribbean, like the agricultural community, receive information about rainfall and its characteristics are through their

Carlos Martinez

carlos.martinez@columbia.edu

1 Department of Earth and Environmental Sciences, Columbia University, New York, NY, USA

2 Lamont-Doherty Earth Observatory, Columbia University, Monell Building, 61 US-9W, Palisades, NY 10964, USA

3 International Research Institute for Climate and Society, Columbia University, Palisades, NY, USA local weather service or climate services (Vaughan and Dessai 2014), who rely on the broader scientific understanding of the rainfall cycle for their forecasts. There is also a need to understand the development of hydrometeorological extremes (i.e. droughts and floods), which have historically impacted the societal and economic welfare in the Caribbean (NOAA 2005; ODPEM 2010; FAO 2016; OCHA 2015, 2016).

Previous work (Martinez et al. 2019, hereafter M19) described regional variations of the Caribbean climatological rainfall cycle at a high temporal resolution, analyzed the regional climatological moisture budget, and addressed the dynamical processes associated with the annual march of the hydrological cycle. The Caribbean rainfall cycle generally covers the months of April through November (Giannini et al. 2000; Chen and Taylor 2002; Taylor et al. 2002; Allen and Mapes 2017; M19). As described in M19, this entire rainy interval is characterized by three seasonal components: 
the early-rainy season (ERS; mid-April to mid-June), an intermittent relatively drier period known as the midsummer drought (MSD; mid-June to late August) (Magaña et al. 1999), and the late-rainy season (LRS; late August to late November). M19 identified five geographical subregions, each with its unique pattern of rainfall distribution throughout the rainy season: the Northwestern Caribbean, the Western Caribbean, the Central Caribbean, the Central and Southern Lesser Antilles, and Trinidad and Tobago/ Guianas. Each sub-region distinguishes itself also in the relative importance of the three main-drivers of moisture convergence in the larger Caribbean region: the North Atlantic Subtropical High (NASH), and the Eastern Pacific and Atlantic Intertropical Convergence Zones (ITCZ). NASH is a semi-permanent system of high-pressure (Davis et al. 1997) that induces strong easterly trade winds and subsidence (Giannini et al. 2000; Wang and Lee 2007; M19) on its southern flank and southeasterlies and convergence on its western flank (M19). The movement and strength of NASH's western flank of convergence is largely responsible for the annual bimodal cycle in the Central Caribbean and its early and weak ERS, and the annual bimodal cycle in the Northwestern Caribbean and its prominent MSD and early LRS demise. The Atlantic and Eastern ITCZ are zonal bands of convergence (Henderson-Sellers and Robinson 1986; Hastenrath 2002) that move meridionally on a 1-2month lag of the solar insolation cycle (Mitchell and Wallace 1992; Waliser and Gautier 1993). The movement of the Eastern Pacific ITCZ, and NASH are largely responsible for the annual bimodal cycle and its weaker MSD in the Western Caribbean. The Atlantic ITCZ and NASH are largely responsible for the unimodal annual cycle in the Eastern Caribbean and its non-existent ERS and MSD, and the Atlantic ITCZ alone is responsible for the bimodal annual cycle of Trinidad and Tobago/Guianas.

There are two regional-features that modify the extent of moisture provided by the main facilitators: the Atlantic Warm Pool (AWP) and the Caribbean Low-Level Jet (CLLJ). The AWP is a region of warm summer-time sea surface temperatures (SSTs). It forms over the Western Caribbean and Gulf of Mexico in May and expands into the Caribbean Sea by the summertime (Wang et al. 2006; M19). It enhances moisture convergence by weakening NASH and its southwestern flank (Wang and Lee 2007), and enhancing precipitable water across the ITCZ (Wang et al. 2008). The CLLJ is a low-level zonal jet centered at $925 \mathrm{mb}$ between Northern South America and the Greater Antilles (Amador 1998, 2008; Amador et al. 2000; Muñoz et al. 2008). The CLLJ is predominantly known for its association with the MSD where it produces a moisture couplet of convergence across the Western Caribbean and divergence across the Caribbean Sea (Muñoz et al. 2008; Hidalgo et al. 2015; Herrera et al. 2015; M19).
The contributions from the large-scale atmospheric circulation have been documented for the annual cycle of rainfall in the Caribbean (M19). A natural assumption may be that the year-to-year variability of Caribbean rainfall is governed by variability in those same elements. But what are the large-scale climate modes of variability that may have a significant impact on the SSTs, NASH, the CLLJ, and the regional ITCZ? One can also ask whether the dominant modes of variability impacting the Caribbean change with season, and if so if the interannual variability of the ERS is linked to that of the LRS? While climatologically, the local influences of the NASH, the trade winds, and the ITCZ vary by region, their interannual variability occurs largely in concert, such that a strengthened NASH and enhanced trade winds are connected and both are associated with a southern displacement of the ITCZ, and vice versa (Giannini et al. 2001b; Wang 2007; Hidalgo et al. 2015). It stands to reason that although the Caribbean rainfall regions do experience different governing mechanisms, climatologically, the interannual variations of the mechanisms affecting interannual variability are in sync and that nearly the entire Caribbean experiences anomalous wetness or dryness during each rainy season. An important exception may be the NW Caribbean, as a recent study found that in many years when droughts were pervasive throughout most of the Caribbean, drought was not experienced in Southern Florida, the Bahamas, and Cuba; a similar spatial pattern of impact was found in Caribbean pluvial years (Herrera and Ault 2017). Hence, one may ask how uniform is the interannual variability of the ERS and LRS over the Caribbean?

Several studies have attributed the interannual variability of the Caribbean to two large-scale climate modes of variability: The El Niño-Southern Oscillation (ENSO) and the North Atlantic Oscillation (NAO). In the Caribbean, ENSO was found to affect both the ERS (Giannini et al. 2000, 2001c; Chen and Taylor 2002; Taylor et al. 2002; Gouirand et al. 2012), during boreal spring, when ENSO events end, and the LRS during boreal fall when events are mature (Giannini et al. 2000, 2001c; Taylor et al. 2002; Spence et al. 2004; Wang et al. 2006; Rodriguez-Vera et al. 2019)., Other studies found no significant correlation between ENSO and rainfall in the Central and Eastern Caribbean (Chen and Taylor 2002; Malmgren et al. 1998; Torres-Valcárcel, 2018; Hernández Ayala 2019) and showed instead that in those regions, rainfall is highly correlated with the NAO (Malmgren et al. 1998; Giannini et al. 2001c; Gouirand et al. 2012; Mote et al. 2017). The NAO, which exhibits peak variability in the boreal winter months, affects the Hadley Circulation and corresponding NASH (Wang 2001), SSTs in the tropical North Atlantic region (TNA) (Bjerknes 1964; Kushnir 1994; Seager et al. 2000; Hurrell et al. 2003; Kushnir et al. 2006) and 
consequently rainfall, during the Caribbean ERS (George and Saunders 2001; Giannini et al. 2001c; Rodriguez-Vera et al. 2019).

The literature varies on how and what large-scale climate drivers affect the Caribbean, because most Caribbean-wide papers looked only at ENSO (Giannini et al. 2000; Chen and Taylor 2002; Taylor et al. 2002; Spence et al. 2004 Wang et al. 2006) or NAO (George and Saunders 2001). Recent papers that have considered both ENSO and NAO only focused on a specific region of the Caribbean (Gouirand et al. 2012; Mote et al. 2017; Torres-Valcárcel 2018; Hernández Ayala 2019). Only a handful of studies investigated both ENSO and NAO across the entire Caribbean (Giannini et al. 2001a, b, c; Rodriguez-Vera et al. 2019), yet they stop short of translating how these large-scale drivers affect the dynamical processes that affect each Caribbean sub-region found in M19. In addition, numerous studies investigating the interannual variability of rainfall in the Caribbean use less-resolved temporal resolutions of the ERS and LRS (i.e. bi-monthly or seasonal averages) that can mask their temporal and spatial evolutions (Malmgren et al. 1998; Giannini et al. 2000, 2001a, b, c; Chen and Taylor 2002; Spence et al. 2004; Taylor et al. 2002; Wang et al. 2006; Gouirand et al. 2012; Torres-Valcárcel 2018; Hernández Ayala 2019). M19 used both pentad and monthly averages and found that both the ERS and LRS have within-season temporal and spatial evolutions between their early and late phases.

This paper seeks to identify the processes governing the interannual variability of rainfall during the different phases of the annual cycle across the Caribbean $\left(5^{\circ} \mathrm{N}-27^{\circ} \mathrm{N}\right.$ and $60^{\circ} \mathrm{W}-90^{\circ} \mathrm{W}$ ). Temporal and spatial composites of wet and dry years in the Caribbean provide insight towards answering the following questions:

1. What large-scale climate drivers govern the interannual variability of Caribbean rainfall, how do they change throughout the rainy seasons, and how do they relate to the large-scale drivers that govern the climatology?

2. Is there a dependency between the variability experienced in the ERS and LRS that may impart longer leadtime for prediction?

The study is framed such that the interannual variability of rainfall is investigated for the Caribbean as a whole, but sub-regional deviations are also examined.

The manuscript is structured as follows. Section 2 describes the data and methods used. Section 3.1 looks at and discusses the homogeneity of the interannual variability of the ERS and LRS in the Caribbean. Sections 3.2 and 3.3 look at and discuss the spatial composites of climate variables pertinent to interannual variability in the Caribbean rainfall cycle during the ERS and LRS, respectively. Section 3.4 investigates the independence of the ERS and
LRS variability. The summary of the results and its implications and concluding remarks are found in Sect. 4.

\section{Data and methods}

\subsection{Data}

This study uses the daily station rainfall dataset from the Caribbean Institute for Meteorology and Hydrology (CIMH) 1969-2017 and NOAA's Global Historical Climatological Network (GHCN) 1960-2016 to investigate the interannual rainfall cycle. Stations are data-stitched across the two observational datasets: missing data in one station's dataset are patched by the other dataset (M19). This process is done only when the stations' coordinates are within a $0.05^{\circ}$ margin from each other. The data are also checked for uniformity by analyzing overlapping years from each dataset. The combined CIMH/GHCN dataset provides historical and fine temporal precipitation data. A total of 38 stations are found; however, only 34 stations are used for this study as stations in the Guianas have a lagged rainfall cycle from the rest of the Caribbean (M19) that would skew the analysis. Station information can be found in Table 1.

To document the dynamically-relevant background state of the seasonal rainfall cycle and its variability, the 1854-2018 $2^{\circ}$ gridded NOAA v5 Extended Reconstructed Sea Surface Temperature (Huang et al. 2017) and 1949-2018 2.5 NCEP/NCAR reanalysis (Kalnay et al. 1996) datasets are used for gridded SST, and sea level pressure (SLP), respectively. For this study we use a monthly temporal resolution from 1960-2016.

Indices for NAO and ENSO are obtained from the NOAA Climate Prediction Center. The NAO Index is derived from a rotated principal component analysis of monthly SLP anomalies (Barnston and Livezey 1987). The index can be found here: https://www.cpc.ncep.noaa.gov/ products/precip/CWlink/pna/nao.shtml. The ENSO Index is the Extended NINO3.4 Index (Huang et al. 2017). The index can be found here: https://www.cpc.ncep.noaa.gov/ data/indices/. For both indices a monthly temporal resolution is used from 1960-2016.

For moisture budget analysis, this study uses the European Centre for Medium-Range Weather Forecasts Interim Re-Analysis (ERA-Interim; Dee et al. 2011) to examine interannual changes in the regional moisture budget. The ERA-Interim is used at a 6-hourly temporal resolution from 1979 to 2016 , at 26-pressure levels, and a $1.5^{\circ}$ by $1.5^{\circ}$ spatial resolution. For further details on the moisture budget calculation please refer to Seager and Henderson (2013) and to Sect. 2.2.2 of M19. 
Table 1 List of rainfall stations used in the study

\begin{tabular}{|c|c|c|c|c|c|}
\hline \multirow[t]{2}{*}{ Station ID } & \multirow[t]{2}{*}{ Station } & \multicolumn{2}{|c|}{ Location } & \multicolumn{2}{|l|}{ Data } \\
\hline & & Lat/Lon & & $\begin{array}{l}\text { Valid years } \\
\text { (Total years) }\end{array}$ & Missing data (\%) \\
\hline 1 & BC B. In. AP. Antigua and Barbuda & 17.135 & -61.791 & $46(57)$ & 0.79 \\
\hline 2 & Nassau Intl. AP., Bahamas & 25 & -77.5 & $43(48)$ & 5.89 \\
\hline 3 & CIMH, Barbados & 13.148 & -59.624 & $48(48)$ & 0.00 \\
\hline 4 & Grantley Intl AP., Barbados & 13.08 & -59.485 & $45(45)$ & 0.00 \\
\hline 5 & Cfarm, Belize & 17.2 & -89 & $40(48)$ & 2.45 \\
\hline 6 & Intl. AP., Belize & 17.53 & -88.3 & $52(57)$ & 0.33 \\
\hline 7 & Georgetown, Cayman & 19.3 & -81.3 & $45(50)$ & 0.41 \\
\hline 8 & Camaguey, Cuba & 21.24 & -77.51 & $50(56)$ & 0.80 \\
\hline 9 & La Habana, Cuba & 23.1 & -82.21 & $51(55)$ & 0.79 \\
\hline 10 & DCAP, Dominica & 15.547 & -61.2993 & $39(42)$ & 0.61 \\
\hline 11 & Santo Domingo, D.R. & 18.25 & -69.58 & $25(57)$ & 26.33 \\
\hline 12 & Guadeloupe & 16.2 & -61.66 & $44(57)$ & 2.16 \\
\hline 13 & Worthy Park, Jamaica & 18.143 & -77.149 & $39(42)$ & 1.35 \\
\hline 14 & Intl. AP., Martinique & 14.59 & -60.99 & $56(57)$ & 0.14 \\
\hline 15 & Hewanorra Intl. AP., St. Lucia & 13.737 & -60.952 & $39(43)$ & 0.15 \\
\hline 16 & Dumbarton, St. Vincent & 13.18 & -61.17 & $43(48)$ & 3.17 \\
\hline 17 & Piarco Intl AP, T\&T & 10.59 & -61.34 & $44(57)$ & 0.00 \\
\hline 18 & Crown Point, T\&T & 11.15 & -60.84 & $44(57)$ & 0.14 \\
\hline 19 & Sunset/Ft. Lauderdale, USA & 26.1 & -80.28 & $54(57)$ & 1.61 \\
\hline 20 & Key West, USA & 24.55 & -81.75 & $56(57)$ & 0.02 \\
\hline 21 & Miami Intl AP, USA & 25.82 & -80.28 & $57(57)$ & 0.00 \\
\hline 22 & Palm Beach AP, USA & 26.68 & -80.08 & $56(57)$ & 0.05 \\
\hline 23 & Henry E. Rohlsen AP, St. Croix & 17.7 & -64.81 & $39(44)$ & 2.55 \\
\hline 24 & Cyril E. King AP, St. Thomas & 18.33 & -64.97 & $25(43)$ & 9.65 \\
\hline 25 & Coloso, USPR & 18.381 & -67.157 & $38(57)$ & 2.61 \\
\hline 26 & Dora Bora, USPR & 18.336 & -66.667 & $42(57)$ & 6.68 \\
\hline 27 & Ensenda, USPR & 17.973 & -66.946 & $49(57)$ & 2.96 \\
\hline 28 & Guaynama, USPR & 17.978 & -66.087 & $35(57)$ & 9.61 \\
\hline 29 & Jajome Alto, USPR & 18.072 & -66.143 & $47(57)$ & 1.49 \\
\hline 30 & Mora Camp, USPR & 18.474 & -67.029 & $44(57)$ & 2.31 \\
\hline 31 & Paraiso, USPR & 18.265 & -65.721 & $44(57)$ & 3.34 \\
\hline 32 & Morovis N, USPR & 18.334 & -66.408 & $54(57)$ & 1.25 \\
\hline 33 & San Andreas, Columbia & 12.583 & -81.717 & $31(55)$ & 15.89 \\
\hline 34 & Felipe, Mexico & 19.7 & -87.9 & $32(57)$ & 12.73 \\
\hline
\end{tabular}

Station ID, station name, location in latitude and longitude, number of valid years from 1960-2017 that have valid pentad data, the total number of years available, and missing data. Missing data shows the percentage of pentads missing two or more days during total number of years

\subsection{Methods}

\subsubsection{Quantifying rainy seasons}

Given the high-frequency noise in daily data, pentad (5-day) averages of daily rainfall observations were calculated for each station. Using similar criteria as Hamada et al. (2002), if a pentad has two or more days of missing data, the pentad was omitted. If a pentad was missing or omitted within the rainfall season, the entire analysis year was omitted for that station. A general definition of the rainfall season is used: from the 17th pentad of the year (centered on March 24th) to the 67th (centered on November 30th). This is done in order to address the different temporal characteristics found in each sub-region (M19). For each station, averages of the ERS precipitation are calculated for every year (from the 21st pentad of the year-centered on April 13 th - to the 34th or June 17th). For every year, each station's seasonal-averaged ERS is subtracted from their longterm climatology. The same procedure is done to calculate 
the seasonal-averaged LRS anomalies (pentads numbered 46 or August 16th to 64 or November 14th relative to the first pentad of the year). Yearly Caribbean-wide ERS and LRS anomalies are calculated by averaging the 34 station's ERS and LRS anomalies.

\subsubsection{Uniformity of Caribbean and dynamical spatial composites}

Caribbean-wide composites are determined as the theorized large-scale phenomena that influence the dynamical mechanisms in the Caribbean encompass the entire region. Each station's ERS pentads and LRS pentads were summed for each year to obtain the total ERS and LRS rainfall for that year. The data for each station's ERS and LRS totals were ranked from driest to wettest. The years with rainfall below the 33rd percentile and above the 66th percentile for a given ERS or LRS are designated as the stations' dry ERS/LRS and wet ERS/LRS year, respectively. If a year is designated as a dry ERS or LRS for at least 15 of the 34 stations, regardless of the station's location, the year was designated as a Caribbean ERS or LRS dry year. A similar procedure was applied for classifying Caribbean ERS and LRS wet years. Using the regional classifications from M19 a cross check was done to make sure that a dense station network in a specific part of the Caribbean was not dominating the rainy season variability analysis. Only two years were omitted from the data filtering (dry LRS, 1986; wet ERS, 1992) as they did not satisfy the cross check. Anomalies of rainfall for the Caribbean ERS and LRS dry and wet years were calculated as percent-normal. The Caribbean-wide composite years are shown in Table 2.

Using the years designated for composting (Table 2), spatial composites from detrended (over 1960-2016) ERS and LRS wet and dry years were created for SST and SLP over the $180^{\circ} \mathrm{W}$ to $15^{\circ} \mathrm{E} ; 20^{\circ} \mathrm{S}$ to $75^{\circ} \mathrm{N}$ domain. The ERS and LRS wet and dry years were also calculated for moisture transport and convergence over the $120^{\circ} \mathrm{W}$ to $15^{\circ} \mathrm{W}$; $4.5^{\circ} \mathrm{S}$ to $75^{\circ} \mathrm{N}$ domain. Anomalies between the composite and the climatology were calculated. A two-sample $t$ test is conducted in order to investigate statistical significance at the 90th confidence level.

\section{Results and discussion}

\subsection{Uniformity of Caribbean interannual variability}

Most of the Caribbean experiences anomalous dry or wet conditions at the same time, as evidenced in the rainfall anomalies in percent-normal for the composite dry and wet ERS (Fig. 1a, b) and dry and wet LRS (Fig. 1c, d). In Fig. 1, the composites during both dry and wet ERS and
Table 2 Dry and wet ERS, and LRS years

\begin{tabular}{|c|c|c|c|}
\hline \multicolumn{2}{|l|}{ Dry } & \multicolumn{2}{|l|}{ Wet } \\
\hline ERS & LRS & ERS & LRS \\
\hline $1967 *$ & $1976 *$ & $1969 *$ & 1979 \\
\hline $1973 *$ & 1981 & 1979 & 1984 \\
\hline $1974 *$ & $\underline{1983}$ & 1981 & 1985 \\
\hline $1975^{*}$ & 1987 & $\underline{1983}$ & 1988 \\
\hline 1985 & 1991 & $\underline{1986}$ & 1996 \\
\hline 1989 & 1992 & 2004 & 1998 \\
\hline 1991 & 1997 & 2005 & 1999 \\
\hline 1994 & 2002 & $\underline{2009}$ & 2005 \\
\hline 1997 & 2009 & 2010 & $\underline{2008}$ \\
\hline 1999 & $\underline{2012}$ & 2011 & 2010 \\
\hline 2001 & 2015 & $\underline{2012}$ & 2011 \\
\hline 2008 & & 2013 & \\
\hline 2014 & & & \\
\hline 2015 & & & \\
\hline
\end{tabular}

Years only in bold denote years where the ERS and LRS are the same. Years bolded, italicized and underlined denote years where the ERS and LRS are opposite. Years with asterisk are years not in the mean flow moisture budget ERA-Interim reanalysis

LRS, respectively, show the magnitude of the anomalies in the NW Caribbean to be weaker than the rest of the Caribbean. In particular, during some years of the composite (not shown) certain stations in the NW Caribbean experienced the opposite signal to the rest of the Caribbean. This is expected, as several studies found similar results in their analyses (Giannini et al. 2001b; Chen and Taylor 2002; Spence et al. 2004; Herrera and Ault 2017). Finally, the Central and Lesser Antilles have the largest percent anomalies in comparison to the rest of the Caribbean in the ERS (Fig. 1a, b). As a whole, the composites capture the largely uniform dryness or wetness across the Caribbean well. However, the differences seen between the NW Caribbean and the rest of the Caribbean, and the large rainfall anomalies in the Central and Lesser Antilles hint that the set of dynamical processes that correspond to each sub-region are being affected differently than each other.

\subsection{Relationship between ERS and ENSO/NAO}

There is a tripolar SST pattern in the North Atlantic Basin, including the Caribbean Sea, in the dry minus wet ERS years during the Winter Dry Season (WDS; December to April; Fig. 2a). The SST tripole exhibits a large tongue of colder than normal SSTs across the southern flank of the TNA and Caribbean Sea. To the north, there is a warm tongue 
(a)

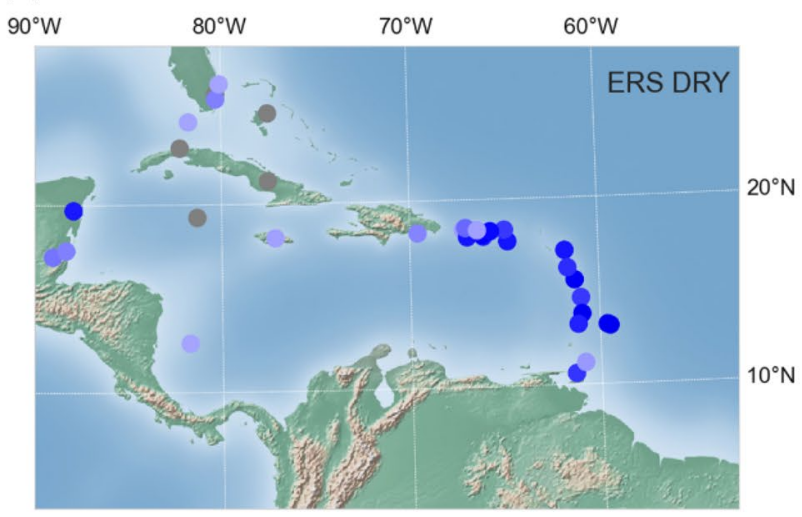

(c)

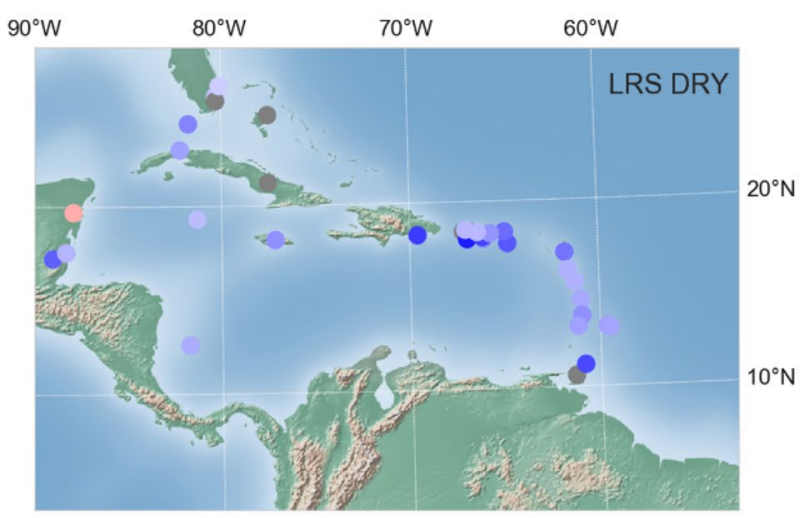

(b)

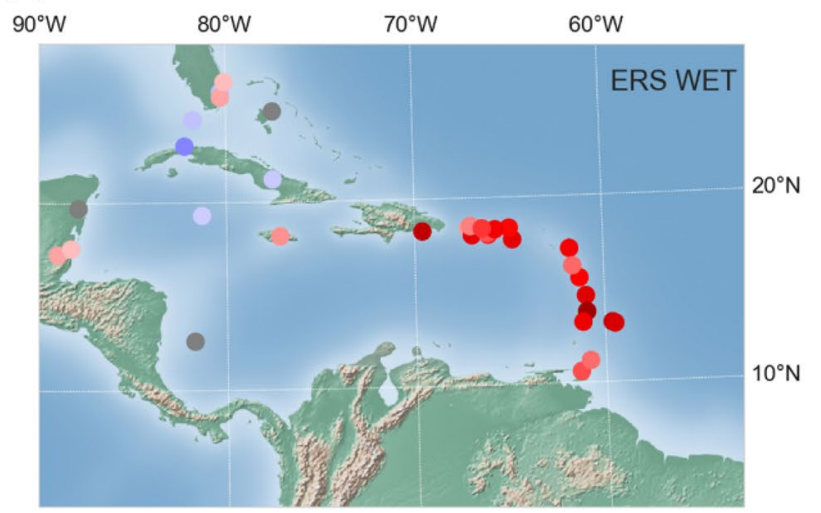

(d)

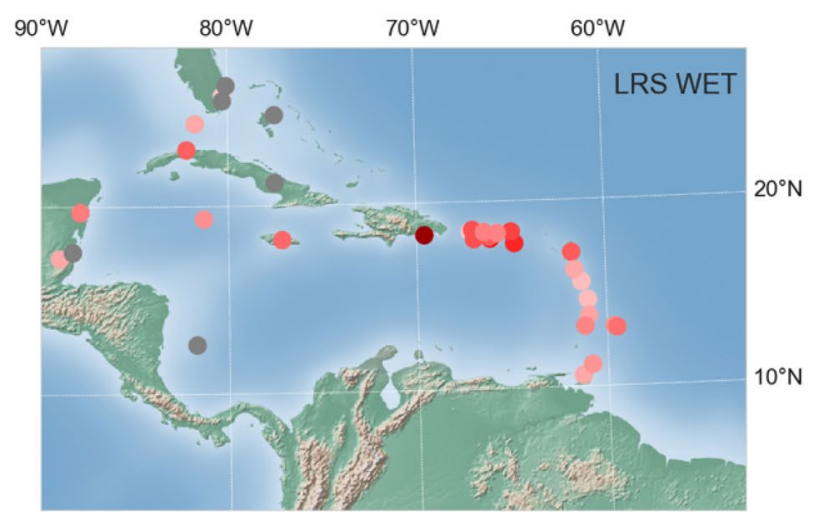

Percent Anomalies

$-100$

$-75$
$-25$

Fig. 1 Wet and Dry ERS (top) and LRS (bottom) composite mean percent anomalies for each station. Blues denote negative departures from each station's climatological ERS and LRS. Reds denote

across portions of the NW Caribbean, Gulf of Mexico, and northern edge of the TNA. The northern part of the tripole consists of another cold SST center in the subpolar gyre region. Centered over the North Atlantic subtropical region and extending into the TNA and Caribbean Sea during the WDS is a large anomalous, positive SLP region (Fig. 2f). Meanwhile areas across Greenland and Iceland show large anomalous negative SLPs (Fig. 2f). In the equatorial Eastern Pacific, anomalous negative SSTs and positive SLPs are seen during the preceding WDS, but these weaken and become non-significant by May and throughout the rest of the year. In May, the southern TNA and Caribbean Sea cold SSTs intensify and the warm, northern TNA SST tongue shrinks and weakens (Fig. 2b). Warm SSTs emerge over the Gulf of Guinea and the Benguela Current region along the coast of South Africa. Of the SLP WDS dipole, the only significant remnant by May is a region of anomalously positive positive departures from each station's climatological ERS and LRS. Grey denotes percent anomalies between -10 to $10 \%$ of the mean seasonal value

SLP in the southwestern TNA and the Caribbean (Fig. 2g). This anomalous SLP center roughly overlaps the region of negative SST anomalies of this month. By June, the warm SST signal in the northern flank of the TNA diminishes and is no longer significant, while the cold SST signal in the southern TNA/Caribbean Sea and warm SST signal along western South Africa persists (Fig. 2c). In addition, the region of significant positive SLP anomalies contracts further into the western and NW Caribbean while the rest of the North Atlantic does not display any large, coherent significant anomalies. The South Atlantic shows some anomalous negative SLP anomalies. Following the ERS, the Caribbean Sea cold SSTs weaken but remain significant for the MSD (Fig. 2d; July-August) and LRS (Fig. 2e; September-November). The South African coast warm SST signal weaken by the MSD and become non-significant by the LRS. Anomalously positive SLPs (Fig. 2i) remain in 
SST

(a)

(b)
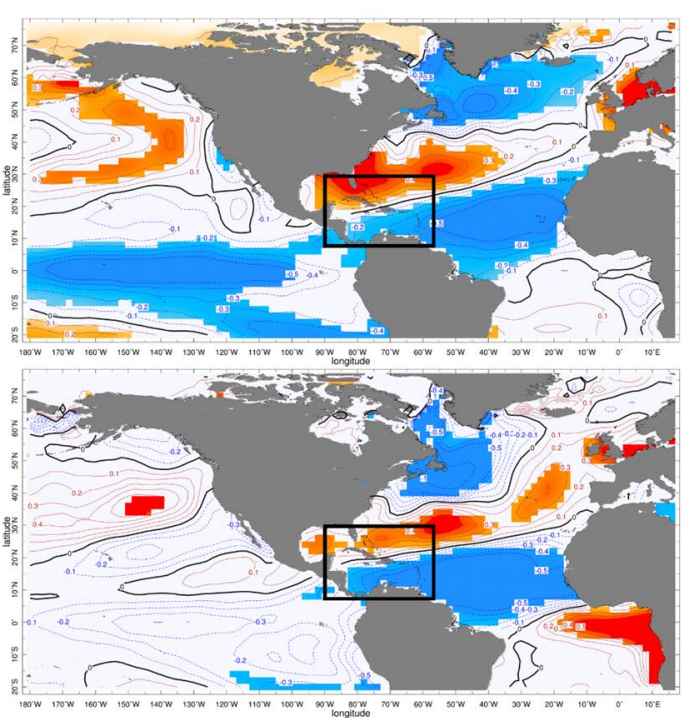

(c)

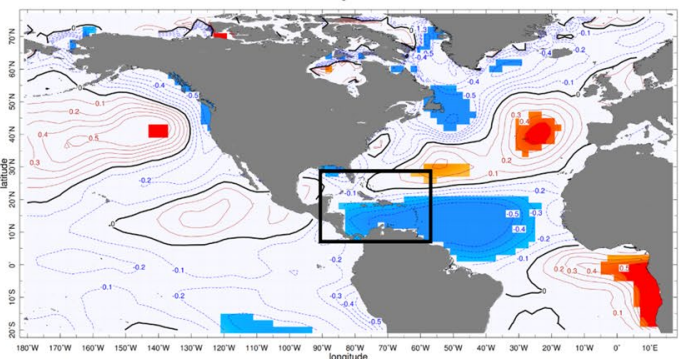

(d)

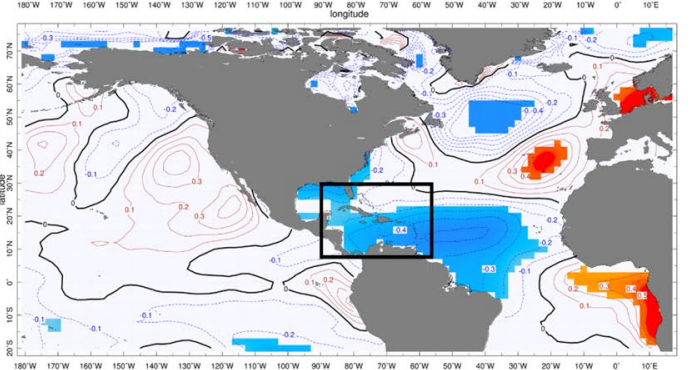

(e)

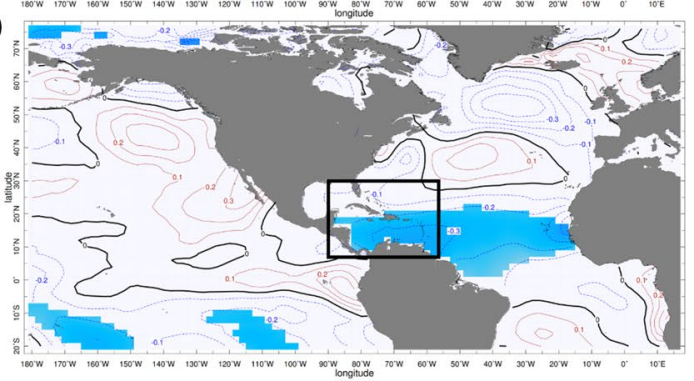

WDS

(f)

ERS
May

ERS

June

MSD

(i)

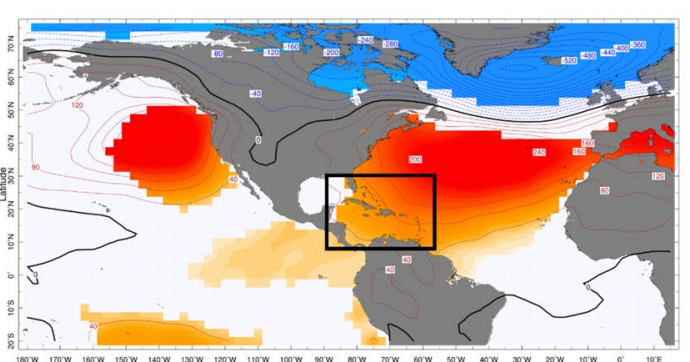

(g)

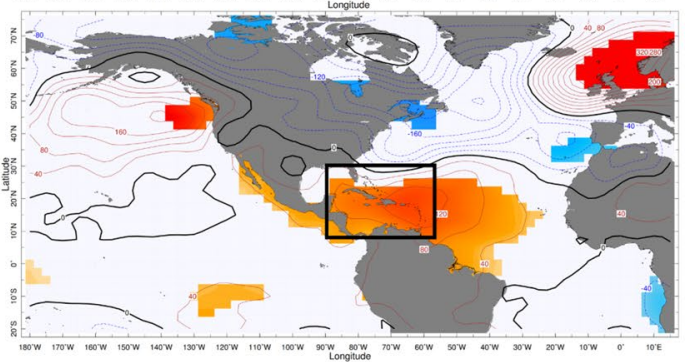

(h)

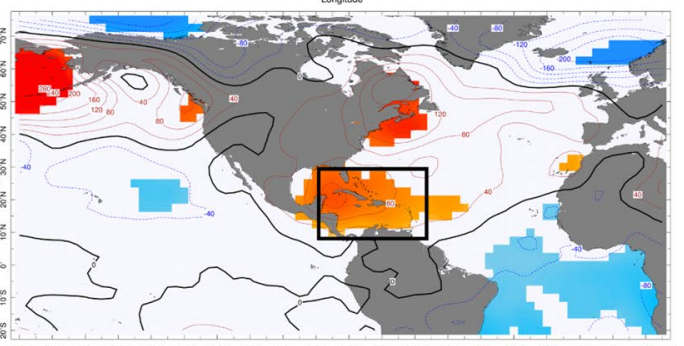

LRS

(j)
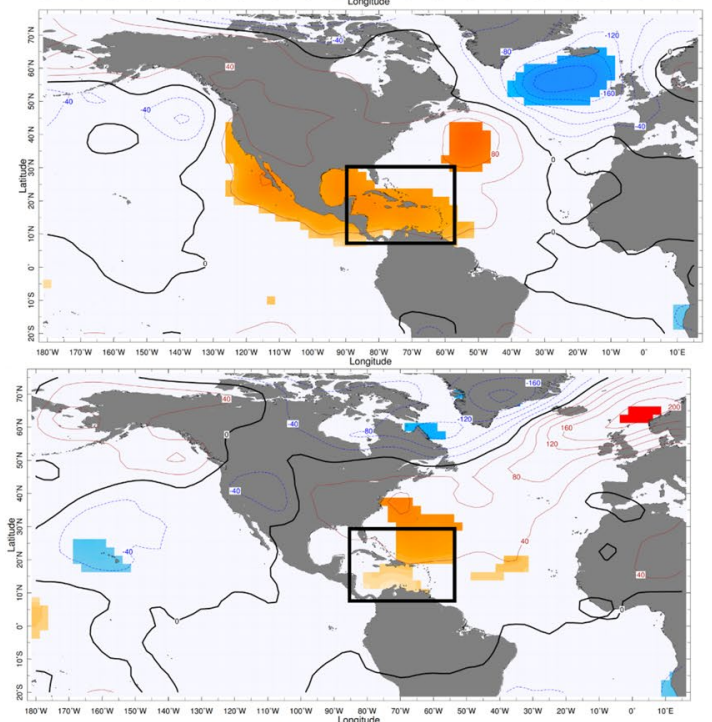

\begin{tabular}{|c|c|c|c|}
\hline$-0.4^{\circ} \mathrm{C}$ & $\begin{array}{l}-0.2^{\circ} \mathrm{C} \\
\text { Anomalous }\end{array}$ & $\begin{array}{l}0^{\circ} \mathrm{C} \\
\text { is SST }(\operatorname{deg} \mathrm{C})\end{array}$ & $0.4^{\circ} \mathrm{C}$ \\
\hline-400 & $\begin{array}{l}-200 \\
\text { Anomalous }\end{array}$ & $\begin{array}{l}0 \\
0\end{array}$ & 400 \\
\hline
\end{tabular}

Fig. 2 Early rainy season dry-year minus wet-year SST (left) and SLP (right) composite anomalies for Dec-Apr WDS (a, f), ERS (b, c, g, h), Jul-Aug MSD (d, i), and Sep-Nov LRS (e, j). Black box indicates the Caribbean domain. Contours are the anomalous SSTs and SLPs with colors denoting significance at $90 \%$ according to a two-sample t-test 
the Caribbean during the MSD; however, the magnitude of anomalous SLP decreases as significant values are seen only in the Caribbean Sea and the Gulf of Mexico and along the Central American, Eastern Pacific coastlines. By the LRS there are little to no statistically significant SLP anomalies in the Caribbean (Fig. 2j) or the rest of the North Atlantic.

The spatial patterns of both the SST and SLP anomalies during the WDS implicates the WDS NAO in affecting dry and wet ERS anomalies in the Caribbean region. To quantify the relationship, lagged-correlations between the NAO index with the Caribbean averaged ERS rainfall anomalies are calculated, with the NAO index moving through every overlapping three-month season, starting from the November of the previous year and ending in the following year's February. There is a moderate, negative correlation between the preceding winter NAO and the ERS rainfall (Fig. 3a), with the DJF and JFM correlations at -0.316 and -0.342 , respectively, and significant at the $1 \%$ level (assuming that yearly values are independent of one another). A similar calculation is performed using an index for ENSO (Fig. 3a) and with the exception of MAM $(-0.287$ at 95 th significance), ENSO exhibits elevated, but not significant, correlations during the WDS and early spring. Therefore, of the two phenomena being examined, the NAO seems to be the most relevant climate mode that impacts the ERS rainfall variability. We will return to discuss the possible role of ENSO in the ERS below.

During the WDS with a positive NAO phase, the Hadley Circulation (Wang 2001) and NASH intensify and cause enhanced trade winds and westerlies, south and north of the anticyclone center, respectively. The observed (Fig. 2) ocean surface temperature response to the positive winter NAO phase is consistent with numerous previous studies (e.g., Cayan 1992; Seager et al. 2000; Chiang and Vimont
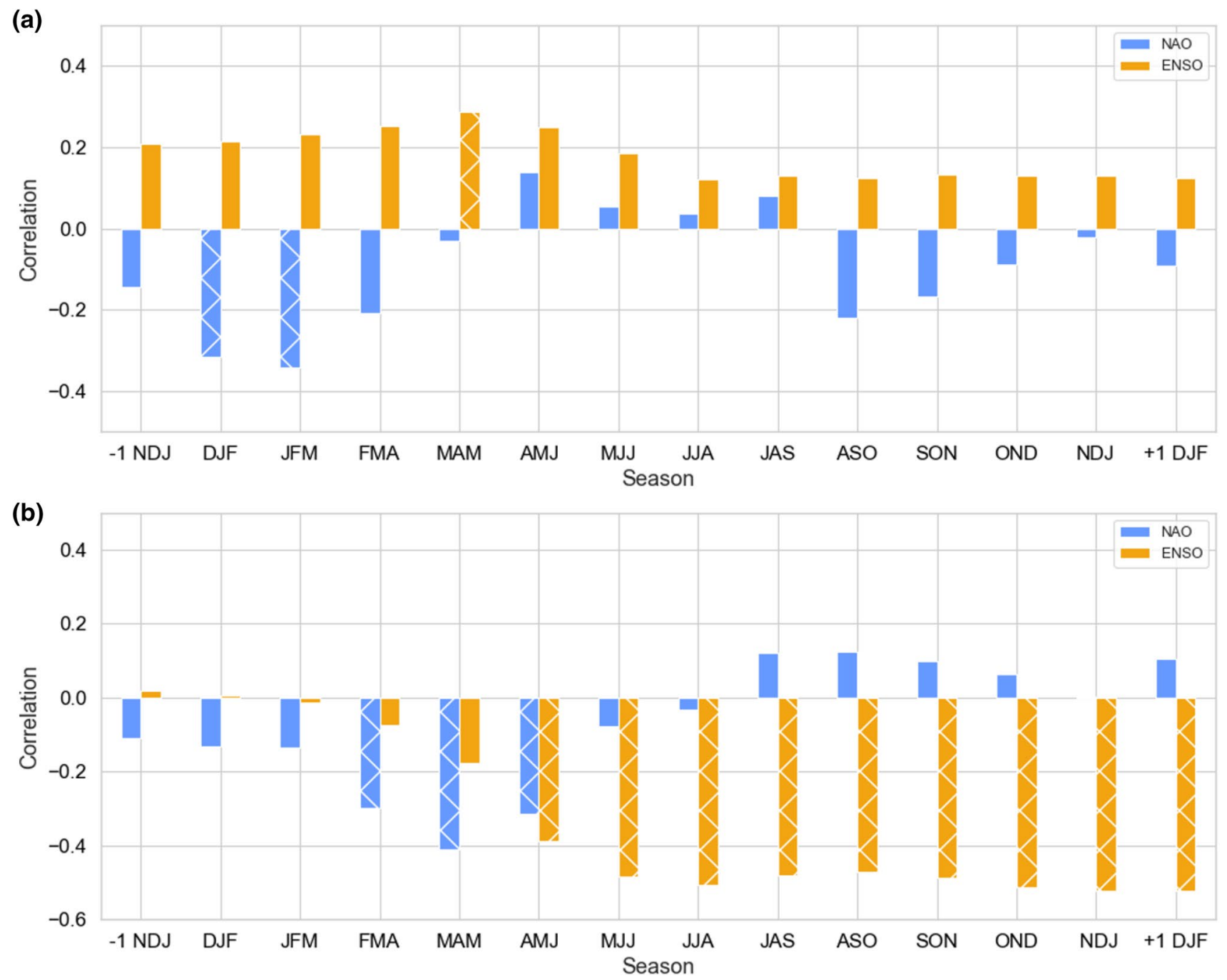

Fig. 3 Correlations between seasonal means of NAO (blue) and ENSO (orange) and Caribbean-wide anomalous ERS (top) and LRS (bottom). Hatching denotes significance at the 95th confidence interval level 
2004; Czaja et al. 2002; Kushnir et al. 2002; Marshall et al. 2001; Gouirand et al. 2012). In the Gulf of Mexico and NW Caribbean the warm SST signal falls within a region where, in the climatology, westerlies are found during the WDS (M19). The intensified NASH blocks the intrusion of cold, dry continental air from North America into the northwest Caribbean during the WDS and the SST there respond with anomalous warming (Reding 1992; Schultz et al. 1998; Giannini et al. 2000; Seager et al. 2000; Sáenz and DuránQuesada 2015; M19).

By the time of ERS, the NAO is typically not very strong (Kushnir et al. 2006), and there are no significant correlations between spring-time SLP or the NAO indices and ERS anomalies (Fig. 3a). However, it is evident that the previous winter NAO induces a SST signal in the Caribbean, which persists during the ERS. This is similarly suggested in previous studies (Giannini et al. 2000, 2001a; Hu et al. 2011), and can be explained by the wind, evaporation, and SST feedback (WES; Xie and Philander 1994; Chang et al. 1997). Under a positive NAO phase, the SST gradient between the cold SST signal in the Caribbean Sea and the warm SST signal across the NW Caribbean and central TNA produces a localized meridional SLP gradient that intensifies the trades across the Caribbean Sea, enhancing the release of latent heat thus continuing the cold SST signal. The northern Caribbean warm SST signal does not persist as long as its cold SST counterpart, which seems to explain the rainfall suppression in the region (see more below). In the climatology, the westerlies seen in the Gulf of Mexico/NW Caribbean and central TNA during the WDS migrate northward during the ERS (M19); therefore, the enhanced easterlies would weaken the westerly-induced warm SST signals in both the Gulf of Mexico/NW Caribbean, and the central TNA. The climatological AWP, which initializes during the ERS, strengthens in the Gulf of Mexico and NW Caribbean due to the persistence of the anomalous warm SSTs created in the earlier season. However, in the Caribbean Sea, the AWP would weaken as a consequence of enhanced coastal upwelling and the SST cold signal in the Caribbean Sea. The SST and SLP patterns demonstrate that the NAO-SST/ SLP persistent signal decays by the MSD and disappears by the LRS.

The NAO-SST/SLP persistent signal affects the moisture flow and convergence pattern in the Caribbean during the ERS. The mean flow component of the moisture budget dominates the climatology of the Caribbean rainfall cycle (M19). The mean flow component further breaks down into its mass convergence and moisture advection sub-components. Following M19, where mass convergence was shown to dominate the total mean moisture convergence, we examine here only the mass convergence term (Fig. 4).

The mass convergence composites are mostly consistent with the anomalous SLP composites and support what has been suggested about the changing wind-field across the Caribbean during the dry-wet ERS year. There appears to be some discrepancy between the mean flow transport composite (Fig. 4) and SLP composite (Fig. 2); however, the corresponding surface winds composites (not shown) justify the anomalous circulation patterns implied in the SLP composites. The dry minus wet composites show an anomalous anticyclonic circulation in the TNA with enhanced easterlies across the Caribbean during the WDS (not shown). In May, the anomalous anticyclonic flow in the composite dry-wet year differences is centered over the western TNA and Caribbean Sea (Fig. 4a). On the southeastern flank of the anomalous anticyclonic circulation, anomalous moisture divergence is found with anomalous, northerly flow, across the Caribbean Sea and southern TNA. In the May climatology, an anticyclonic circulation dominates over the southwestern TNA associated with the western flank of NASH. This, in turn, is associated with moisture divergence west of the Lesser Antilles and a convergence band over the Central Caribbean (M19, Fig. 3e). The anomalous circulation in dry-wet Mays expands NASH, stretching its western flank further into the Caribbean Sea and enhancing the climatological divergence seen in the Caribbean Sea. This would weaken the climatological southeasterlies in the Caribbean Sea and along the Central American coast, and as a result enhance the CLLJ. The enhancement of the CLLJ would enhance divergence in all but the Nicaragua to Costa Rican coastline, as this coastline climatologically experiences zonal convergence from the CLLJ (Hidalgo et al. 2015; M19). This explains why there is little to no anomalous divergence across this portion of the Western Caribbean (Fig. 4). Simultaneously, the band of climatological convergence in the Central Caribbean shifts to the northwest, causing the NW Caribbean and Central Caribbean to receive anomalous convergence and divergence, respectively. The resulting shift in the convergence band explains how this study (Fig. 1a) and others (i.e. Jury et al. 2007; Allen and Mapes 2017; Herrera and Ault 2017) find a weakened dry signal or in some cases an anomalous wet signal in the NW Caribbean while the rest of the Caribbean experienced dryness during the ERS.

In June (Fig. 4b), the dry-wet year anomalous anticyclonic circulation cell shifts westward and northwestward to affect the entire Caribbean Island chain. As a result, anomalous northerly flow and divergence is seen across the entire Caribbean. The anomalous flow is associated with a weakened western flank of NASH convergence band and a more easterly flow across the Caribbean Sea and NW Caribbean, where southeasterlies are seen in the June mean-flow climatology (M19, Fig. 3f). The anomalous northerly-northeasterly flow over the Caribbean Sea and southern Central America turns easterly in the Eastern Pacific and a weak divergence-convergence dipole in the Eastern Pacific marks 
(a)

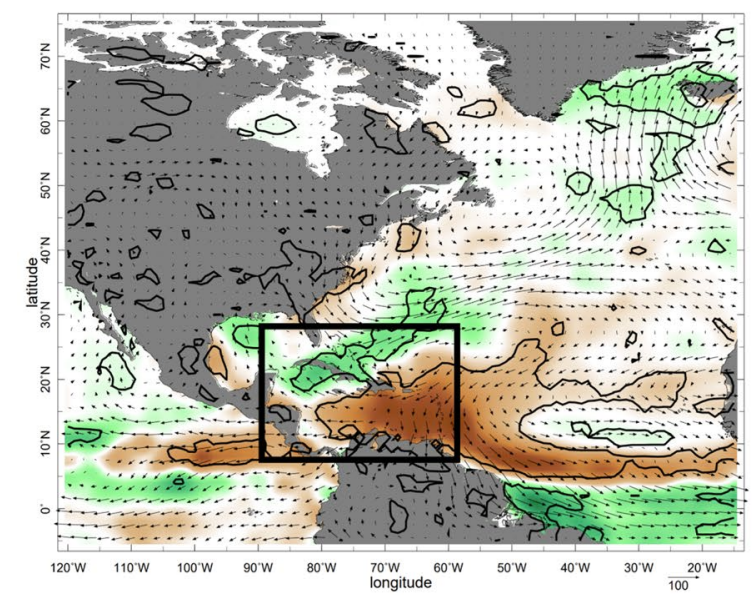

(b) ERS JUNE

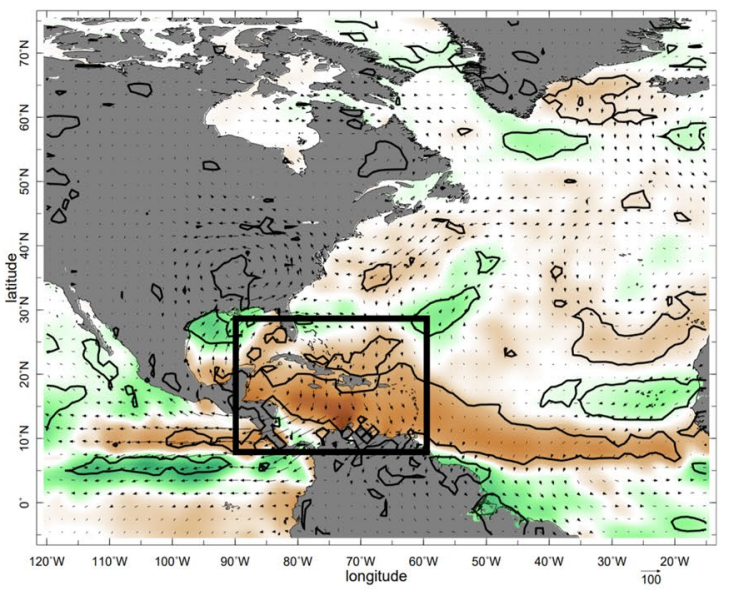

(c)

MSD

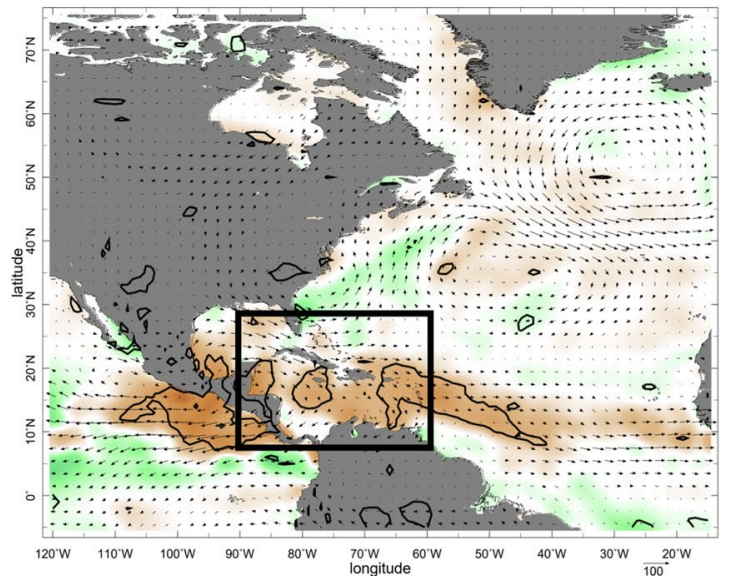

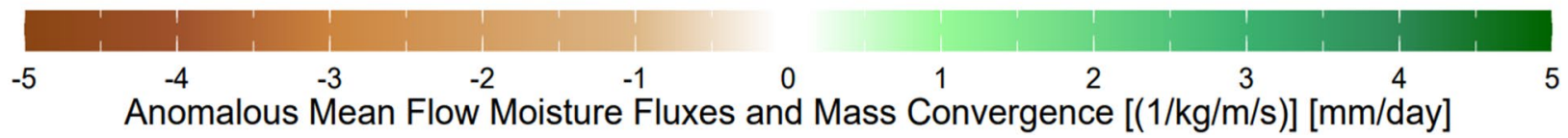

Fig. 4 Early rainy season dry-year minus wet-year mass convergence (colors) and fluxes (vectors) composite anomalies for ERS (a, b) and JulAug MSD (c). Black box indicates the Caribbean domain. Contours denote significance at the $90 \%$ according to a two-sample t-test

the southern displacement of the ITCZ convergence band there, as is the case in the equatorial Atlantic. This is consistent with how a strengthened CLLJ has been associated with a southward displacement of the Eastern Pacific ITCZ (Hidalgo et al. 2015). The southern displacement of the Atlantic ITCZ explains why the Central and Southern Lesser Antilles have the largest change in percent rainfall anomalies during dry ERS years than any other region (Fig. 1a). Unlike other regions, the Central and Southern Lesser Antilles have only one main facilitator of moisture convergence, the Atlantic ITCZ (M19); therefore, any changes with the Atlantic ITCZ would significantly affect rainfall in the region. The advection of specific humidity enhances dryness across the
Caribbean Sea especially in dry minus wet June's and over the Western Caribbean and Central America (not shown) as a result of the Caribbean Sea to Eastern Pacific anomalous flow. The changes described in the paragraph above occur following a winter with a positive NAO anomaly. The opposite changes occur after a winter with a negative NAO phase and the consequent WES feedback.

The anomalous patterns weaken in the Caribbean by the MSD (Fig. 4c) as the anomalous circulations shift unto Central America, weakly impacting convergence in the Western Caribbean. Some significant anomalous divergence is found across portions of the Lesser Antilles. By the LRS non-significant anomalous flow and convergence are found in the 
Caribbean (not shown). The lack of changes in the moisture budget and transport in the MSD and LRS further support the suggestion that the NAO-SST persistence signal only weakly affects the MSD and LRS.

As indicated above, this study finds (Fig. 3a) a weak connection between the ERS and the mature/post-mature phase of ENSO during the winter preceding the ERS. This connection is consistent with previous studies (Giannini et al. 2000, 2001c; Chen and Taylor, 2002; Taylor et al. 2002; Hu et al. 2011; Gouirand et al. 2012), however, as we describe below, the role of ENSO appears secondary to that of the NAO. The SST and SLP signal in the Eastern Pacific are reminiscent of the winter footprint of a mature ENSO phase from the previous calendar year (Fig. 2a, f) and are indicating the presence of a La-Niña state in the winter preceding a dry ERS. The relationship is weak given the weak ENSO-ERS correlations, similarly to that found in some previous studies (Malmgren et al. 1998; Jury et al. 2007; Torres-Valcárcel 2018). A simple way to evaluate the relative roles of the NAO and ENSO in the ERS is by using Kendall's Tau $(\tau)$, a non-parametric rank correlation coefficient, which takes into consideration issues such as outliers, and the non-gaussian distribution of rainfall. Here, Kendall $\tau$ is used to determine the association between the indices of each climate driver and the ERS anomalies in the Caribbean. DJF and JFM NAO with ERS anomalies produce a Kendall $\tau$ of 0.182 and 0.201 , respectively, which indicates a constructive non-trivial role for the NAO. DJF and JFM ENSO with ERS anomalies produce a Kendall $\tau$ of 0.155 and 0.170 , respectively, also indicative of a constructive, albeit weaker role. When DJF NAO and DJF ENSO are combined, they produce a Kendall $\tau$ of 0.208 , indicating that there is added value in accounting for the state of ENSO in ERS variability. However, JFM NAO and JFM ENSO combined produce a value of 0.195 , less than the association with NAO alone, signifying that JFM ENSO does not play a supporting role to the NAO in the late winter. This ENSO supporting role is likely due to the effects post-mature ENSOs have on springtime SSTs in the tropical Atlantic. In this case, the aftermath of a cold phase of ENSO is linked with a wintertime negative Pacific-North-American (PNA) teleconnection pattern, with a high-pressure anomaly over the TNA, which enhances the trade winds, and consequently decreases TNA SSTs. (Wang 2001). Under a positive NAO phase, this enhances the local NAO impact on TNA SSTs and its persistence onto the ERS. Under a negative NAO phase, this dampens the local NAO impact on TNA SSTs and its persistence onto the ERS.

Finally, the weak to moderate correlations of NAO/ENSO and ERS variability may suggest that other climate drivers are affecting ERS variability. However, there are no other regions outside of the Eastern Pacific and Atlantic basins in the global spatial composites of the ERS (not shown) that show significant SST or SLP anomalies, which suggests there are no other climate drivers inducing the SST or SLP signal over the Atlantic. The weaker correlations between the climate drivers and ERS variability is likely due to the existing incoherence seen between the Northwestern Caribbean and the rest of the Caribbean. Although the entire Caribbean experiences the same climate driver, its effects on the Northwestern Caribbean during portions of the ERS is opposite to the rest of the Caribbean. Therefore, the ERS regional average may reflect this, and result in lower correlations. Furthermore, the SST and SLP composites (Fig. 2a-d, f-i) in the equatorial Atlantic is similar to the Atlantic Meridional Mode (AMM) a non-ENSO coupled ocean/atmosphere variability in the Atlantic basin (Servain 1991), of which has been found to be forced by the NAO (Chiang and Vimont 2004). This further suggests that the TNA SST signal is induced by the NAO.

\subsection{Relationship between LRS and ENSO/NAO}

Unlike dry minus wet composite ERS years, dry minus wet composite LRS years (Fig. 5a-f) display a strong SST signal in the Eastern Pacific and a less pronounced signal in the Atlantic. During the preceding WDS, a weak SST tripole is found in the North Atlantic, somewhat reminiscent of the tripole found during the WDS during dry minus wet ERS years (compare Fig. 5a to Fig. 2a). SLPs during the WDS show an anomalous dipole pattern in the extratropical North Atlantic. Specifically, there are anomalous positive SLPs centered between $45^{\circ} \mathrm{N}$ and $50^{\circ} \mathrm{N}$ and anomalous negative SLPs over Greenland and Iceland (Fig. 5g). There are negative SSTs and positive SLPs over the South Atlantic, and in the Equatorial Pacific the opposite is found. Although there is little significance in the anomalous SSTs or SLPs in the Caribbean during the WDS, and there are no significant correlations between wintertime ENSO and NAO with anomalies of the LRS (Fig. 3b), the spatial pattern in the North Atlantic looks somewhat reminiscent of the NAO. This may be due to how some wet and dry LRS years coincide with wet and dry ERS years (Table 2).

During the ERS for dry minus wet LRS years, the North Atlantic SST (Fig. 5b) and SLP (Fig. 5h) pattern disappears. The sole significant residual in the North Atlantic is an anomalous cold SST band in the equatorial Atlantic. In the Eastern Pacific, anomalous and significant warm SSTs (Fig. 5b) and a negative SLP anomaly (Fig. 5h) emerge. During the preceding MSD (Fig. 5c), the Eastern Pacific SST anomalous signal strengthens as does the equatorial Atlantic anomalous cold SST signal, which now extends into the Caribbean Sea. In the northern TNA, a significant signal of warm SSTs emerges. A tongue of positive SLP stretching from the South Atlantic to the Gulf of Mexico is seen while in the Eastern Pacific a negative SLP anomaly persists (Fig. 5i). The spatial Eastern Pacific-Caribbean dipole of 
SST

(a)

(b)
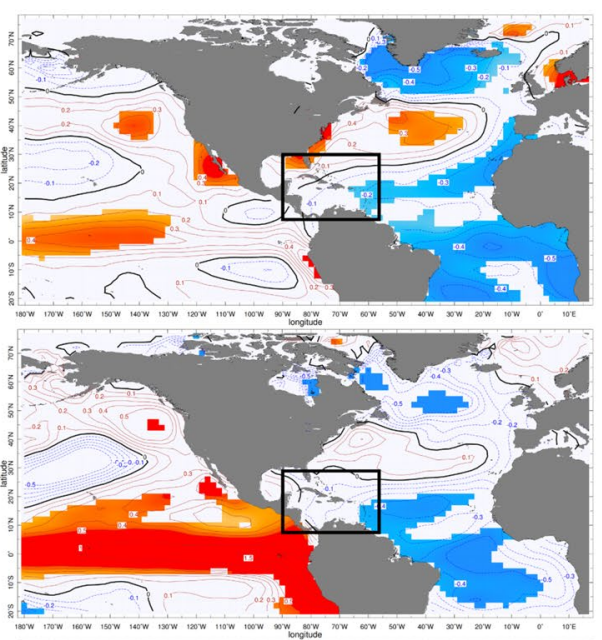

(c)

(d)
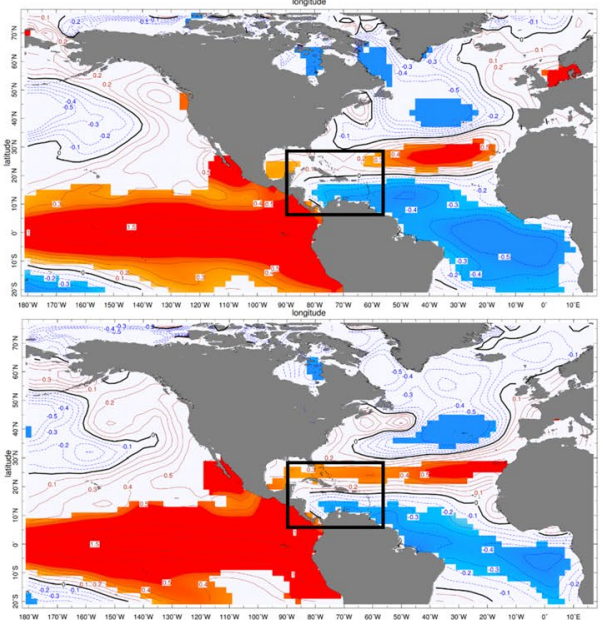

(e)

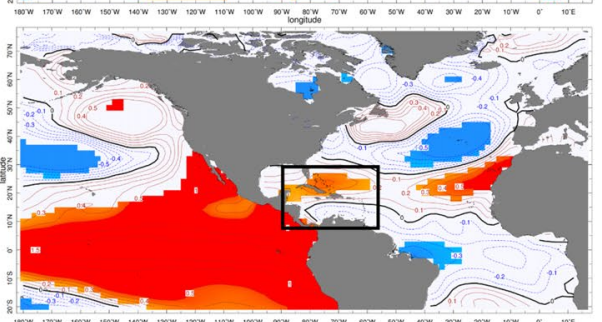

(f)

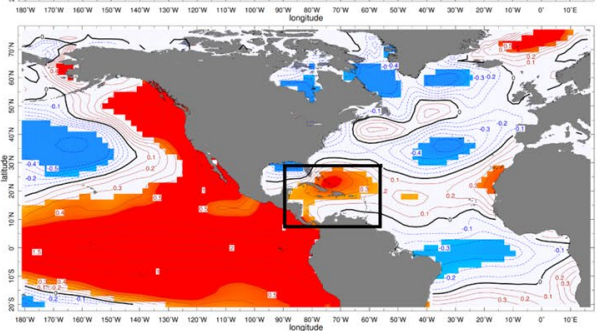

WDS

ERS

MSD

(h)

(g)

SLP
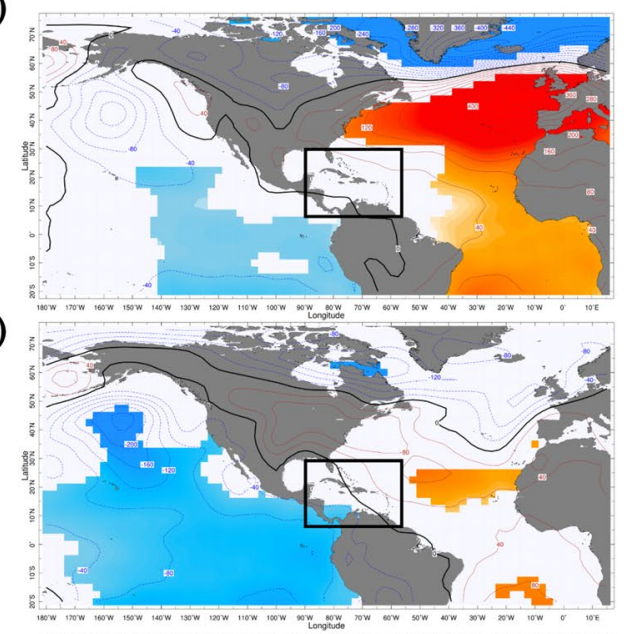

(i)

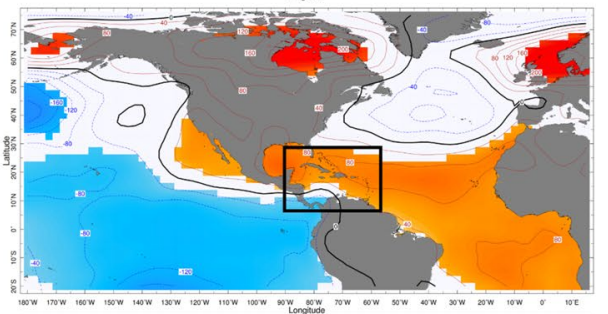

(j)

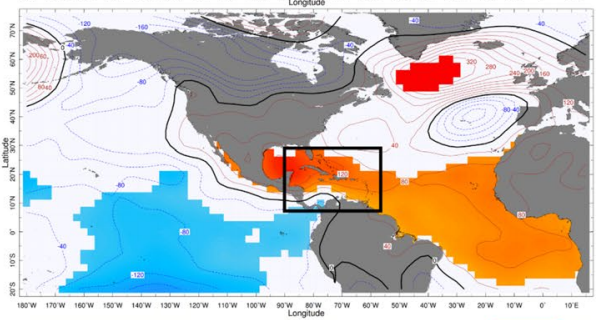

(k)

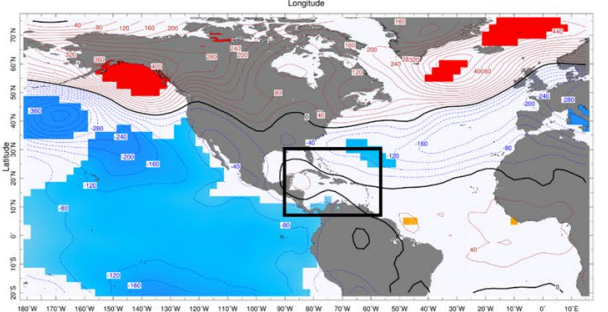

(I)

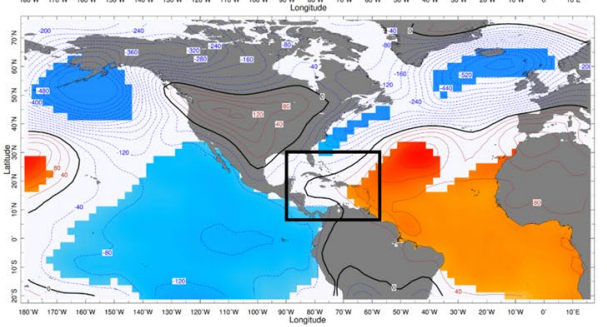

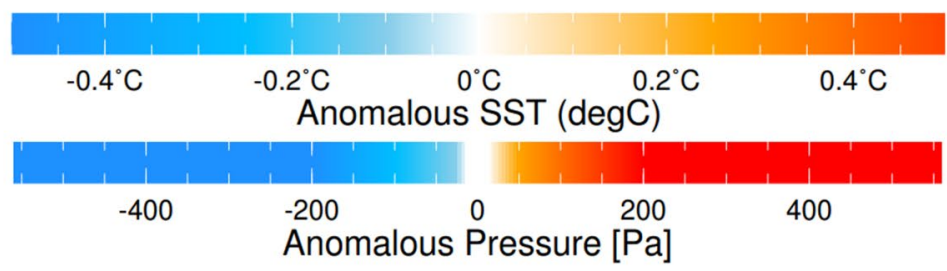


४Fig. 5 Late rainy season dry-year minus wet-year SST composite anomalies for Dec-Apr WDS (a, g), May-June ERS (b, h), Jul-Aug MSD (c, i), and LRS (d-f, $\mathbf{j}-\mathbf{l})$. Black box indicates the Caribbean domain. Contours are the anomalous SSTs with colors denoting significance at $90 \%$ according to a two-sample t-test

SLPs and SSTs during the ERS and MSD in the Eastern Pacific are consistent with an El Niño state. ENSO indices during the late-spring and summertime are significantly and negatively correlated with Caribbean-averaged LRS anomalies (Fig. 3b) at the 99\% confidence level, suggesting that El Niño (La Niña) is associated with the LRS dry (wet) conditions. In response to the emerging El Niño, a cold SST anomaly and an anomalous high-pressure anomaly form over the Tropical Atlantic (Curtis and Hastenrath 1995; Poveda and Mesa 1997) through an ENSO atmospheric bridge (Giannini et al. 2000). In the early summer, during warm events, the anomalous anticyclonic circulation across the Caribbean Basin results in enhanced trade winds across the southern TNA and Caribbean Sea and weakened trade winds across the northern TNA and north of the Caribbean Sea. The latter results in a warm SST band via weakened air-sea fluxes. The anomalous wind flow in the southern TNA funnels through Central America and onto the Eastern Pacific Basin as a result of the SLP seesaw pattern between the Eastern Pacific and Caribbean basins (Giannini et al. 2000). The opposite occurs during the initialization of a cold ENSO event.

It is important to note however that there are also some significant and negative correlations between spring-time NAO indices and the LRS anomalies (Fig. 5b). FMA, MAM, and AMJ NAO indices have correlations of $-0.297,-0.416$, and -0.315 , respectively. The FMA and AMJ correlations are significant at the $95 \%$ confidence level and during the MAM they are significant at the $99 \%$ confidence level. The findings are inconsistent with the composites in Fig. 5, as there is no indication of the characteristic SST and SLP patterns that are associated with the NAO during the ERS. This remains a subject for further investigation.

The SLP and SST pattern seen in the MSD persists into the LRS. The warm SST signal in the TNA, now extends into the NW Caribbean (Fig. 5d-f). The cold SST signal in the Eastern Pacific continues (Fig. 5d-f). Although the Eastern Pacific negative SLP anomalies continue (Fig. 5d-f), some notable SLP changes are seen in the Atlantic Basin. The high-pressure Caribbean anomaly diminishes in October (Fig. 5k). In November, a dipole of anomalous SLPs emerges with negative SLPs in the NW Caribbean and Eastern U.S. Seaboard, and positive anomalous SLPs in the Eastern Caribbean and Equatorial Atlantic (Fig. 51). It is evident from the spatial composite months coinciding with the LRS that ENSO and its atmospheric bridge effect during the MSD continue into the
LRS. ENSO indices during the boreal Fall and +1 Winter are significantly and negatively correlated with LRS anomalies (Fig. 3b). The SLP spatial composite during anomalous LRS Novembers is similar to numerous ENSO composite studies which found warm ENSO composites to show anomalous high SLPs over the TNA and anomalous low SLPs over Greenland in November, and vice versa for cold ENSO composites (Moron and Gouirand 2003; Fereday et al. 2008; King et al. 2018; Ayarzagüena et al. 2018). In addition, warm ENSO composites in $(+1)$ January thru March have Atlantic SLP anomalies that are opposite to what are found in November and December, and vice versa for cold ENSO composites, suggesting SLPs in the Atlantic with respect to ENSO are inverted between the early and late halves of the WDS (Moron and Gouirand 2003; Fereday et al. 2008; King et al. 2018; Ayarzagüena et al. 2018).

It is understandable that ENSO and its associated Eastern Pacific and Caribbean Sea SLP seesaw pattern would affect moisture flow in the Caribbean during the LRS. It would be important to determine whether or not the differences seen in the early and late phases of the LRS from the SST/SLP composites are also seen in how moisture is fluxed in the Caribbean and how the dynamical processes that drive the climatological LRS are affected. We begin with the MSD during anomalous LRS years as the WDS and ERS moisture transports do not directly affect the LRS rainfall.

The mean flow moisture transport anomalies (Fig. 6) are, as anticipated, consistent with anomalous SLP composites. The LRS dry minus wet composite during the MSD through most of the LRS show anomalous easterlies and divergence over the Caribbean with an anticyclonic circulation over the Gulf of Mexico (Fig. 6a-c). North of the Caribbean are anomalous westerlies associated with an anomalous cyclonic circulation seen across the northern subtropical Atlantic. In addition, a strong convergence band over the Eastern Pacific with anomalous easterlies north of $\sim 10^{\circ} \mathrm{N}$ are found (Fig. 6a-d). From the climatological MSD and LRS moisture budget in M19, the anomalous easterlies and convergence in the Eastern Pacific shown during dry years is consistent with the enhanced northeasterly flow on the northern flank of the climatological Eastern Pacific ITCZ convergence band and reduces the southeasterly flow on its southern flank. This means that the climatological convergence band is displaced southward. In addition, the Atlantic ITCZ band weakens with anomalous divergence over the region during dry years. The climatological, western flank of NASH convergence band begins its southeasterly movement from the NW Caribbean in September to the Central Caribbean by October (M19, Fig. 5e, f). Therefore, the resulting pattern in dry years suggests that convergence on the western flank of NASH is (1) relatively normal across the NW Caribbean and (2) weaker across the Central Caribbean. 


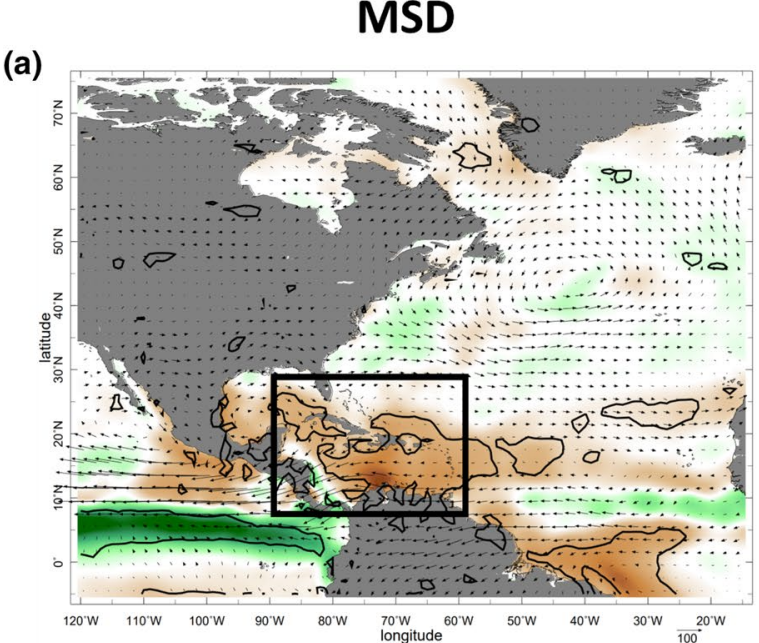

LRS OCT

(c)

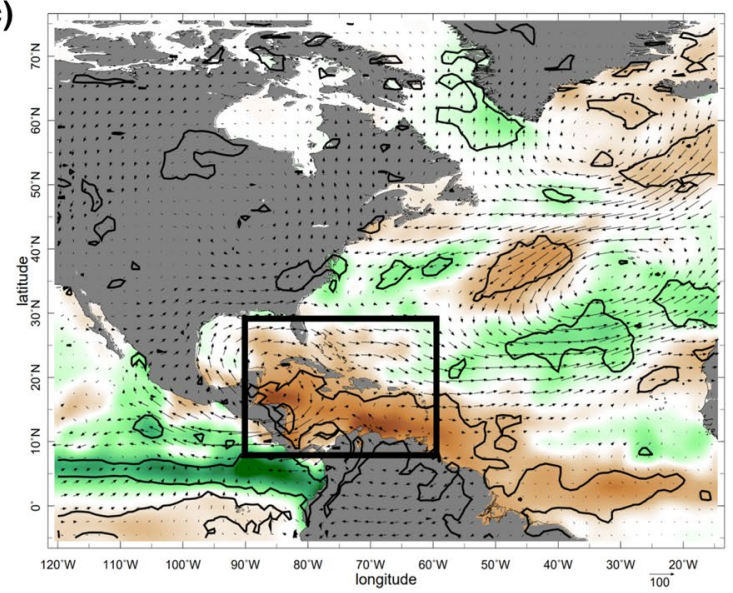

LRS SEP

(b)

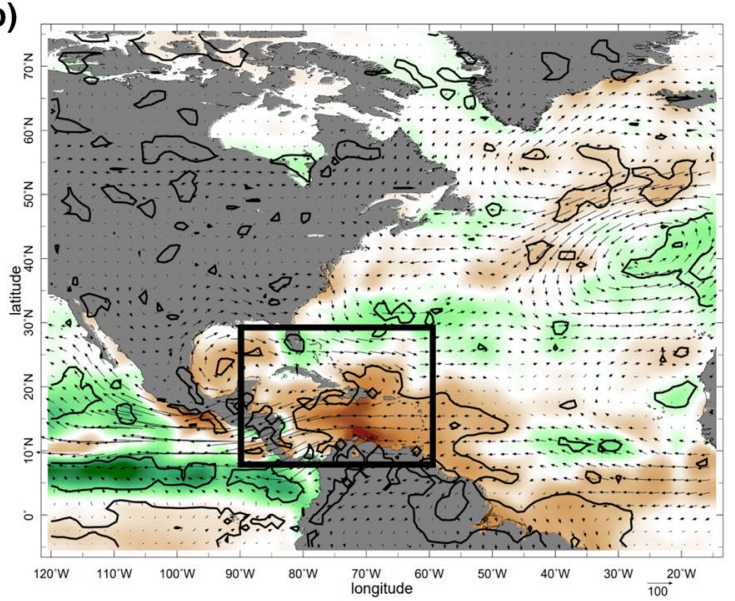

LRS NOV

(d)

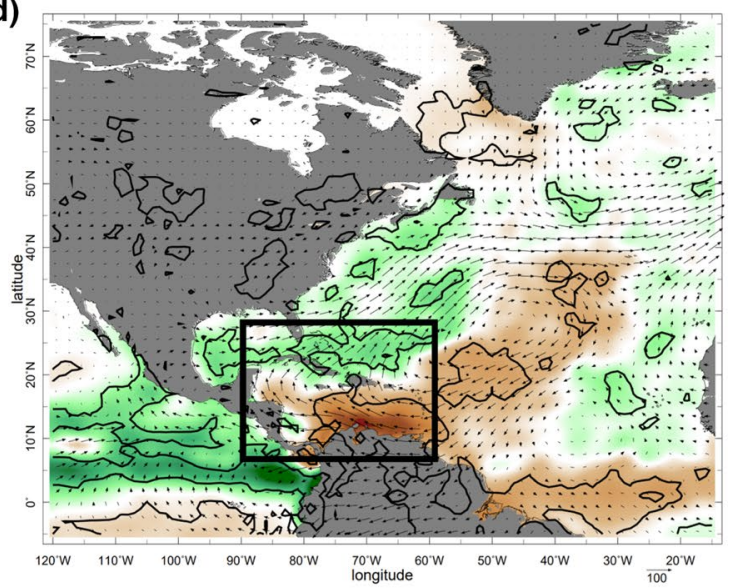

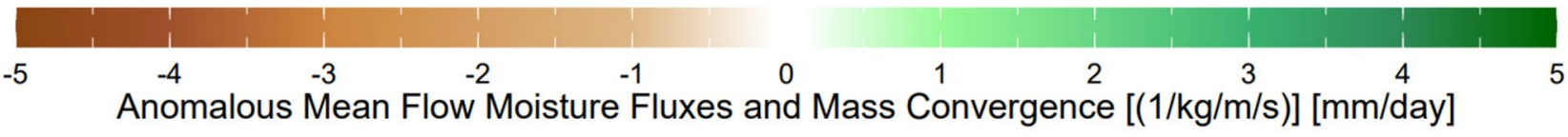

Fig. 6 Late rainy season dry-year minus wet-year mass convergence (colors) and fluxes (vectors) composite anomalies for Jul-Aug MSD (a), and LRS (b-d). Black box indicates the Caribbean domain. Contours denote significance at the $90 \%$ according to a two-sample t-test

Although the anomalous pattern continues in the Eastern Pacific and Atlantic basins in November, several changes are found in the Caribbean basin. Dry minus wet Novembers show an anomalous anticyclonic circulation over the TNA (Fig. 6d). On the southeastern flank of the anomalous circulation are anomalous divergence and southeasterlies across the Caribbean Sea, On the northwestern flank of the anomalous circulation are southwesterlies and convergence over the Greater Antilles and NW Caribbean. The anomalous convergence from the advection of specific humidity enhances the anomalous convergence band from mass convergence onto the mean flow (not shown). Based on the climatological November pattern (M19, Fig. 5c, f), in dry years Caribbean regions on the southeastern flank of the anomalous pattern would experience strengthened divergence and easterlies while Caribbean regions on the northwestern flank of the anomalous pattern would experience weakened divergence and easterlies. The opposite would be seen in wet Novembers, where an anomalous cyclonic circulation appears over the TNA. Clearly, the ENSO induced SLP signal can impact the demise of the LRS across the Caribbean. This finding may explain how this study and others (Giannini et al. 2001b; Chen and Taylor 2002; Spence et al. 2004; Herrera and Ault 2017) find weakened dryness 
or anomalous wetness in the NW Caribbean while the rest of the Caribbean experiences dryness during Caribbean LRS dry years, and the opposite during Caribbean LRS wet years. This finding also suggests that the displacement of the subtropical jet as a result of ENSO during the winter (Giannini et al. 2001b; Spence et al. 2004; Kushnir et al. 2006) is not the sole reason for the difference in the anomalous signal between the NW Caribbean and the rest of the Caribbean, as the November divergence-convergence couplet is seen in the mean flow of the moisture budget. Although there is not a definitive conclusion as to how ENSO produces the Atlantic SLP signal in November (Bladé et al. 2008; Ineson and Scaife 2009; King et al. 2018; Ayarzagüena et al. 2018), this study is in congruence with Ayarzagüena et al. (2018) suggestion that ENSO-related perturbations to precipitation anomalies over the Caribbean basin are responsible for the teleconnection to the North Atlantic.

Finally, changes with the AWP and CLLJ, regional modifiers of the LRS (M19), would be seen. With a warm ENSO event, the anomalous easterlies strengthen the CLLJ which would enhance dryness across most of the Western Caribbean and Central Caribbean. The exception is across the Nicaraguan to Costa Rican coastlines where, climatologically, it receives zonal convergence by the CLLJ (Hidalgo et al. 2015; M19). An enhancement of the CLLJ enhances zonal convergence in this region and explains the anomalous convergence seen there (Fig. 6). The cold SSTs over the southern TNA would weaken the AWP that is climatologically seen in the southern TNA (M19, Fig. 5). The climatological AWP in the southern TNA is located where the Atlantic ITCZ is (M19); therefore, the weakening of the AWP would contribute to the drying of the southern edge of the Caribbean island chain associated with the southern displacement of the Atlantic ITCZ. In the NW Caribbean and Gulf of Mexico, the AWP would be normal or strengthened, which weakens the extent of anomalous divergence in the region. Given the linear relationship seen in the composites, the changes of the dynamical processes during dry years would be opposite during wet years during the initialization of cold ENSO events.

\subsection{Independency of the ERS and LRS}

The findings of the dynamical spatial composites give reason to suggest that the ERS and LRS are independent of each other. To quantify the independence of the ERS and LRS, the Caribbean-averaged ERS and LRS anomalies are correlated. The 1960-2016 time series of ERS and LRS anomalies (Fig. 7) have a correlation of 0.0634 , indicating that the ERS and LRS are uncorrelated. To determine if this is uniform across the entire Caribbean, each station's ERS and LRS anomalies are correlated. 32 of the 34 stations show their anomalous ERS and LRS to be uncorrelated (Table 3). A closer look into the years that are determined for the composites provides further
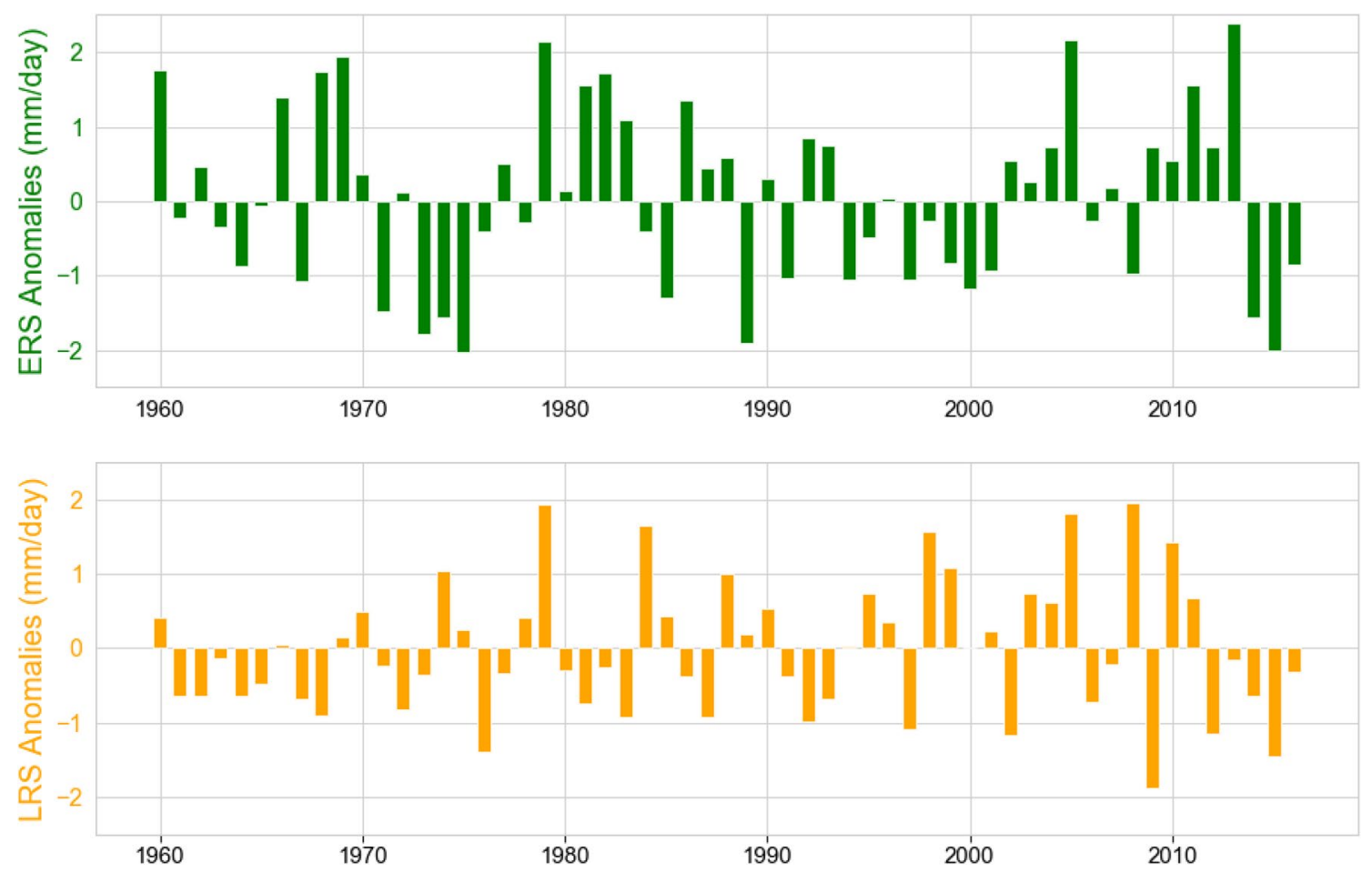

Fig. 7 Year-by-year anomalies of the 34-station averaged ERS (top) and LRS (bottom) from 1960-2016 
Table 3 Correlation coefficients between seasonal-averaged ERS anomalies and seasonalaveraged LRS anomalies for each station

\begin{tabular}{|c|c|c|}
\hline (ID) Region & (ID) Station name & $\begin{array}{l}\text { ERS-LRS } \\
\text { correlations }\end{array}$ \\
\hline \multirow[t]{9}{*}{ Northwest Caribbean } & (2) Nassau, Bahamas & 0.085 \\
\hline & (7) Georgetown, Cayman & 0.132 \\
\hline & (8) Camaguey, Cuba & 0.108 \\
\hline & (9) La Habana, Cuba & 0.028 \\
\hline & (13) Worthy Park, Jamaica & -0.011 \\
\hline & (19) Ft. Lauderdale, USA & 0.225 \\
\hline & (20) Key West, USA & -0.097 \\
\hline & (21) Miami Intl. AP., USA & -0.071 \\
\hline & (22) Palm Beach, USA & 0.041 \\
\hline \multirow{12}{*}{$\begin{array}{l}\text { Central Caribbean/Northern Lesser } \\
\text { Antilles }\end{array}$} & (1) BC Bird Intl. AP, Antigua/Barbuda & -0.113 \\
\hline & (11) Santo Domingo, DR & 0.495 \\
\hline & (23) Henry E. Rohlsen AP., St. Croix & -0.094 \\
\hline & (24) Cyril E. King, St. Thomas & -0.131 \\
\hline & (25) Coloso, USPR & -0.600 \\
\hline & (26) Dora Bora, USPR & -0.095 \\
\hline & (27) Ensenda, USPR & 0.092 \\
\hline & (28) Guaynama, USPR & 0.0193 \\
\hline & (29) Jajome Alto, USPR & -0.033 \\
\hline & (30) Mora Camp, USPR & 0.266 \\
\hline & (31) Paraiso, USPR & 0.201 \\
\hline & (32) Morovis N., USPR & 0.164 \\
\hline \multirow[t]{9}{*}{ Eastern Caribbean } & (3) CIMH, Barbados & 0.015 \\
\hline & (4) Grantley A. Intl. AP., Barbados & -0.064 \\
\hline & (10) DCAP, Dominica & -0.218 \\
\hline & (12) Guadeloupe & 0.045 \\
\hline & (14) Intl. AP., Martinique & -0.169 \\
\hline & (15) Hewanorra, St. Lucia & -0.0168 \\
\hline & (16) Dumbarton, St. Vincent & 0.144 \\
\hline & (17) Piarco Intl AP, T\&T & -0.071 \\
\hline & (18) Crown Point, T\&T & -0.623 \\
\hline \multirow[t]{4}{*}{ Western Caribbean } & (5) CFarm, Belize & 0.104 \\
\hline & (6) Intl. AP., Belize & -0.044 \\
\hline & (33) San Andreas, Columbia & 0.075 \\
\hline & (34) Felipe, Mexico & 0.093 \\
\hline
\end{tabular}

Values in bold denote significance at the $95 \%$ evidence that the ERS and LRS are independent of each other. Of the 57 years in this study, there are 33 years identified (Table 2). Of those, only 7 years had both the ERS and the LRS as both wet or both dry. In contrast, there are 8 years where the ERS and LRS anomalies were opposite to each other (i.e. wet ERS and dry LRS), and 18 years where one portion of the rainfall season experiences anomalous wetness or dryness while the other portion experiences normal conditions (between the 33rd and 66th percentiles). Hence, the variability of the ERS and LRS are independent of each other, as each season has a different dominating large-scale climate driver affecting its interannual variability. The processes that lead to the ERS and LRS anomalies are different. The NAO-SST persistence pattern alone does not persist by the LRS during dry and wet LRS years, suggesting that the LRS is relatively normal during dry and wet ERS years. The onset of ENSO and its associated SLP-seesaw pattern does not materialize during the ERS across the Caribbean; therefore, the ERS is relatively normal during dry and wet LRS years.

\section{Summary and conclusions}

This study analyzes the interannual variability of the seasonal cycle of rainfall in the Caribbean based on precipitation station data from the Caribbean Institute of Climatology 
and Hydrology (CIMH) and NOAA Global Historical Climatological Network between 1960-2016. This study finds the year-to-year variabilities of the ERS and LRS are relatively uniform across the Caribbean, with exception in the NW Caribbean. This study then analyzes Eastern Pacific and Atlantic-wide spatial composites of wet and dry ERS and LRS years for SST, SLP, mean flow moisture convergence and moisture transports. The two wet seasons are impacted in distinctly different ways by two different, and largely independent, large-scale phenomena: ENSO and the NAO. This study finds the interannual variability of the ERS is dominated by persistent anomalous SSTs due to a WES feedback, initiated by the preceding winter NAO. The interannual variability of the LRS is dominated by ENSO and an associated seasonal SLP see-saw between the Eastern Pacific and Caribbean basin/tropical Atlantic. Schematics illustrate the summarized effects of each large-scale climate driver on the climatological rainfall pattern and dynamical mechanisms in the Caribbean (Fig. 8).

As suggested in Sect. 3.2 and Fig. 8a, when a positive NAO phase precedes the WDS, the NAO-SST TNA pattern that persists into spring and early summer through the WES feedback would cause the following changes to the ERS climatological pattern (Fig. 8 of M19): a strengthening and expansion of NASH during the ERS, more easterly flow across the Caribbean Sea, more westerlies across the NW Caribbean, a northwestward shift of the NASH convergence band with a larger SW-NE tilt, weakening of the AWP in the Caribbean Sea but strengthening in the Gulf of Mexico and NW Caribbean, a strengthened CLLJ, and a southern displacement of the ITCZ convergence bands. These changes induce dryness across the entire Caribbean, with a lesser dry (or slightly wet) signal in the NW Caribbean and a weaker dry signal along the Nicaraguan and Costa Rican coastlines. The opposite would occur when the WDS is preceded by a negative NAO phase. Preceding winter mature/post-mature ENSO phases play a secondary role on ERS variability by modifying the NAO induced SST-persistence signal.

El Niño, the warm phase of ENSO, and its associated seasonal SLP see-saw pattern between the Eastern Pacific and Caribbean basins (description in Sect. 3.3; Fig. 8b) would cause the following changes to the LRS climatological pattern (Fig. 8 of M19): a strengthening of the southwestern flank of NASH during the LRS, strengthened easterlies across the Caribbean Sea and southern TNA, weakened easterlies north of the Caribbean Sea and northern TNA, enhanced CLLJ, southern displacement of the Eastern Pacific ITCZ, weakened Atlantic ITCZ across the Lesser Antilles, weakened AWP across the eastern Caribbean Sea and southern TNA, and strengthened AWP across the (a)

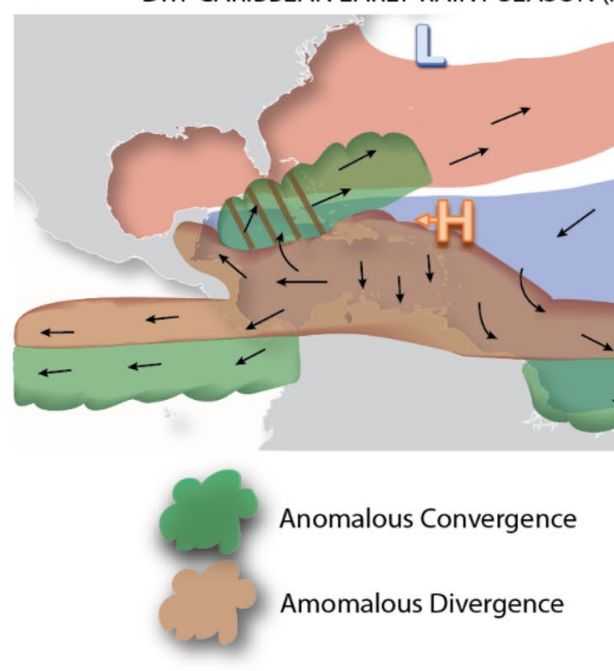

(b)

D) DRY CARIBBEAN LATE-RAINY SEASON (SEPTEMBER-NOVEMBER)

$\longrightarrow$ ERS: Anomalous Winds; LRS: Anomalous Sep-Oct Winds
LRS: Anomalous Nov Winds

Anomalous Convergence and Divergence

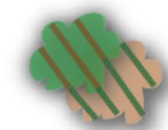

b!n

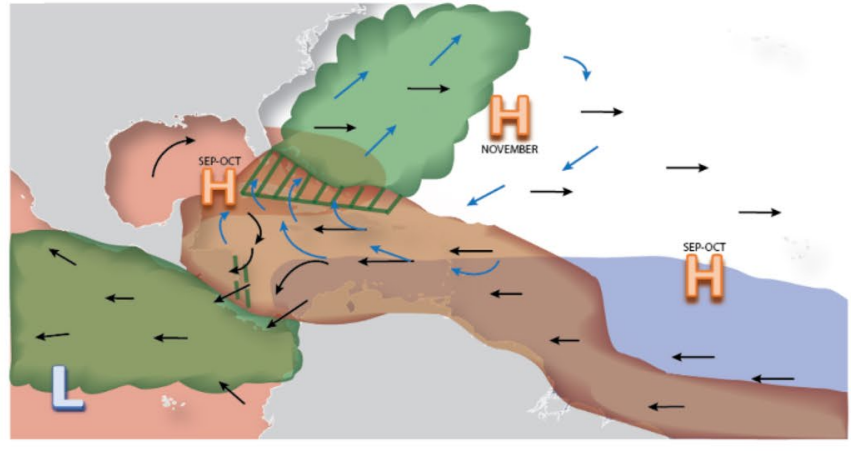

Cooler SSTs

Warmer SSTs
Fig. 8 a Schematic of the anomalous pattern during dry Caribbean early-rainy seasons as a result of preceding winter dry season positive NAO-SST persistence and WES feedback. b Schematic of the anomalous pattern during dry Caribbean late-rainy seasons as a result of the summertime onset of warm ENSO and associated inter-basin see-saw sea-level pressure pattern. Areas shaded in green denote anomalous convergence. Areas shaded in brown denote anomalous divergence. Areas shaded in blue and red denote cooler and warmer sea-surface temperatures, respectively. Black arrows denote the anomalous surface wind pattern. Blue arrows denote the anomalous surface wind pattern in November. Large "H" with denotes an anomalous high. Large "L" denotes an anomalous low. The ERS area with hatched convergence is due to divergence moving into the area as the anomalous High propagates west during the season. The LRS area of hatched divergence is due to the circulation change between September/October and November, producing convergence 
northern TNA, and NW Caribbean. These changes would induce dryness across the entire Caribbean, with a lesser dry signal or wet signal in the NW Caribbean, and along the Nicaraguan and Costa Rican Caribbean coastlines.

Similarly, to M19, this study emphasizes the importance of utilizing pentad and monthly resolutions in order to avoid masking the evolution of the variability of rainfall in the Caribbean throughout the rainy season. For instance, a seasonal composite of the LRS would likely mask the November signal seen in this study, which is important in determining how the Caribbean experiences some differences in its anomalous LRS precipitation signal. In the ERS, composites of the entire season during the ERS would likely dampen the May signal which is important in explaining the differences in anomalous precipitation seen between the Northwestern Caribbean and the rest of the Caribbean.

This study provides several implications and considerations when investigating the predictability of rainfall in the Caribbean. First, it is important to consider whether the predictability of these large-scale climate drivers is uniform across the Caribbean, as each sub-region has distinct sets of dynamical mechanisms which are impacted differently by each climate driver in both space and time. Hence, the predictive skill of the large-scale climate drivers and dynamical mechanisms (i.e. NASH, CLLJ, AWP, ITCZ) should be investigated for each sub-region. Second, it is valuable to investigate the role of intraseasonal variability in addition to the findings of this study on the predictability of the rainfall cycle in the Caribbean. Certain characteristics such as the timing of the rainfall season may be influenced by intraseasonal variability For instance, the Madden-Julian Oscillation (MJO), a natural coupled ocean-atmosphere wave with a cycle of 30-90 days (Madden and Julian 1971), is found to affect the LRS (Martin and Schumacher 2011); therefore, it would be valuable to assess the predictive skill of MJO on timing characteristics of the LRS.

This study provides useful information and a framework for investigating the predictability of the ERS in the Caribbean. Recent studies have found the NAO to be highly predictable via statistical and dynamical models (Scaife et al. 2014; Wang et al. 2017). Therefore, future work will evaluate the predictive skill that the previous winter NAO and the pre-ERS SST-persistence signal it induces has on characteristics of the Caribbean ERS (i.e. onset, duration, demise, seasonal totals). Likewise, the knowledge of the secondary role of ENSO on changes in TNA SSTs can be utilized to examine ENSOs role in affecting characteristics of the ERS. An important consideration would be what domain of SSTs would maximize the predictive skill of the ERS and its variability across each sub-region. For instance, an SST index consisting of southern TNA and Caribbean Sea SSTs may be beneficial for predicting ERS characteristics across the southern and eastern sub-regions of the Caribbean, whereas an SST index across the Gulf of Mexico and Central TNA may inform some predictive skill for ERS characteristics in the Northwestern Caribbean.

This study provides useful information and a framework for investigating the predictability of the LRS in the Caribbean. It is evident that the evolution of ENSO affects the first 2 months of the LRS differently than its final month (November). Therefore, future work would assess the skill that meteorological variables have on characteristics of the LRS (i.e. inter-basin sea-level pressure, surface winds), especially those that pertain to the transition of anomalous rainfall into November. It would also be valuable to investigate the domains of meteorological variables (i.e. the seesaw SLP pattern between the Eastern Pacific and Caribbean basins vs. SLP over the TNA) that would maximize the predictive skill of characteristics of the LRS and its variability across each of the sub-regions.

Models have been found to misrepresent some of the dynamical mechanisms in the Caribbean, and may be responsible for their biases in simulating Caribbean rainfall (Ryu and Hayhoe 2013; Eichhorn and Bader 2017). A likely reason for these systematic biases may be that the models misrepresent the seasonal and temporal evolutions of the climate drivers that affect the dynamical mechanisms within the ERS and LRS. Assessing how current climate models simulate the mean state and variability of the NAO, the NAO-induced SST persistence signal, ENSO, the ENSO induced SLP see-saw effect, may provide insight on these systematic biases and improve the predictability of the rainfall cycle in models.

This study has several implications for investigating climate change impact on rainfall in the Caribbean. Previous studies have shown that there is no observed trend on the annual precipitation of rainfall in the Caribbean. Given that the main drivers of ERS and LRS variability are independent, it would be valuable to assess whether this is because the trends of the climate drivers (Dong et al. 2011; Cai et al. 2014) and processes that respond to them have ERS and LRS trends that negate each other. Future projections in NAO and ENSO from climate change can also be used to assess how they translate to changes in the ERS and LRS, respectively. The better understanding of the interannual variability of the Caribbean rainfall cycle presented in this study could be used to predict the seasonal rainfall cycle, the genesis of hydro-meteorological disasters, and the regional climate effects stemming from large-scale climate drivers.

Acknowledgements We like to thank Alessandra Giannini, Ángel Munoz, Joseph Trujillo, Catherine Pomposi, and Alex Mitchell for useful discussions. We would also like to thank the Caribbean Institute for Meteorology and Hydrology (CIMH) and the National Oceanic Atmospheric Administration (NOAA) for providing the data, and the European Centre for Medium-Range Weather Forecasts for the ERAInterim Reanalysis. This work was funded by ACToday, the first of 
Columbia University's World Projects. YK received support from the U.S. National Science Foundation award AGS-1612904. MT received support from the U.S. National Science Foundation AGS-1607348. We would like to thank the insightful and constructive comments from the reviewers. Finally, CM would like to thank almighty God for the opportunity to unearth science under His Glory.

Open Access This article is licensed under a Creative Commons Attribution 4.0 International License, which permits use, sharing, adaptation, distribution and reproduction in any medium or format, as long as you give appropriate credit to the original author(s) and the source, provide a link to the Creative Commons licence, and indicate if changes were made. The images or other third party material in this article are included in the article's Creative Commons licence, unless indicated otherwise in a credit line to the material. If material is not included in the article's Creative Commons licence and your intended use is not permitted by statutory regulation or exceeds the permitted use, you will need to obtain permission directly from the copyright holder. To view a copy of this licence, visit http://creativecommons.org/licenses/by/4.0/.

\section{References}

Allen TL, Mapes BE (2017) The late spring Caribbean rain-belt: climatology and dynamics. Int J Climatol 37:4981-4993

Amador JA (1998) A climatic feature of the tropical Americas: the trade wind easterly jet. Top Meteor Oceanogr 5(2):1-13

Amador JA (2008) The intra-Americas sea low-level jet. Ann N Y Acad Sci 1146(1):153188. https://doi.org/10.1196/annals.1446.012

Amador JA, Magaña VO, Perez JB (2000) The low level jet and convective activity in the Caribbean. In: Preprints 24th conference in Hurricanes and tropical meteorology. American Meteorological Society, Fort Lauderdale, pp 114-115

Ayarzagüena B, Ineson S, Dunstone NJ, Baldwin MP, Scaife AA (2018) Intraseasonal effects of El Niño-Southern Oscillation on North Atlantic climate. J Clim 31:8861-8873. https://doi. org/10.1175/JCLI-D-18-0097.1

Barnston AG, Livezey RE (1987) Classification, seasonality and persistence of low-frequency atmospheric circulation patterns. Mon Weather Rev 115:1083-1126. https://doi.org/10.1175/15200493(1987)115\%3c1083:CSAPOL\%3e2.0.CO;2

Bjerknes J (1964) Atlantic air-sea interaction. Adv Geophys 10:1-82

Bladé I, Newman M, Alexander MA, Scott JD (2008) The late fall extratropical response to ENSO: sensitivity to coupling and convection in the tropical west Pacific. J Clim 21:6101-6118. https ://doi.org/10.1175/2008JCLI1612.1

Cai W et al (2014) Increasing frequency of extreme El Niño events due to greenhouse warming. Nat Clim Change 4:111-116. https://doi. org/10.1038/nclimate2100

Cayan DR (1992) Latent and sensible heat flux anomalies over the Northern Oceans: driving the sea surface temperature. J Phys Ocean 22:859-881

Chang P, Ji L, Li H (1997) A decadal climate variation in the tropical Atlantic Ocean from thermodynamic air-sea interactions. Nature 385:516-518

Chen AA, Taylor MA (2002) Investigating the link between early season Caribbean rainfall and the El Niño +1 year. Int J Climatol 22:87-106

Chiang JCH, Vimont DJ (2004) Analogous meridional modes of atmosphere-ocean variability in the tropical Pacific and tropical Atlantic. J Clim 17(21):4143-4158

Curtis S, Hastenrath S (1995) Forcing of anomalous sea surface temperature evolution in the tropical Atlantic during Pacific warm events. J Geophys Res 100:15835-15847
Czaja A, Van der Vaart P, Marshall J (2002) Diagnostic study of the role of remote forcing in tropical Atlantic variability. J Clim 15:3280-3290

Davis RE, Hayden BP, Gay DA, Phillips WL, Jones GV (1997) The North Atlantic subtropical anticyclone. J Clim 10:728-744

Dee D et al (2011) The ERA-Interim reanalysis: configuration and performance of the data assimilation system. Q J R Meteorol Soc 137:553-597

Dong B, Sutton RT, Woollings T (2011) Changes of interannual NAO variability in response to greenhouse gases forcing. Clim Dyn 37:1621-1641

Eichhorn A, Bader J (2017) Impact of tropical Atlantic sea-surface temperature biases on the simulated atmospheric circulation and precipitation over the Atlantic region: an ECHAM6 model study. Clim Dyn 49:2061-2075

Fereday DR, Knight JR, Scaife AA, Folland CK, Philipp A (2008) Cluster analysis of North Atlantic-European circulation types and links with tropical Pacific sea surface temperatures. J Clim 21:3687-3703. https://doi.org/10.1175/2007JCLI1875.1

Food and Agriculture Organization of the United Nations (FAO) (2016) Situation report: dry corridor in Central America. FAO, Rome

George SE, Saunders MA (2001) North Atlantic Oscillation impact on tropical north Atlantic winter atmospheric variability. Geophys Res Lett 28:1015-1018

Giannini A, Kushnir Y, Cane M (2000) Interannual variability of Caribbean rainfall, ENSO, and the Atlantic Ocean. J Clim 13:297-311

Giannini A, Cane MA, Kushnir Y (2001a) Interdecadal changes in the ENSO teleconnection to the Caribbean region and the North Atlantic Oscillation. J Clim 14:2867-2879

Giannini A, Chiang JCH, Cane MA, Kushnir Y, Seager R (2001b) The ENSO teleconnection to the tropical Atlantic Ocean: contributions of the remote and local SSTs to rainfall variability in the tropical Americas. J Clim 14:4530-4544

Giannini A, Kushnir Y, Cane MA (2001c) Seasonality in the impact of ENSO and the North Atlantic high on Caribbean rainfall. Phys Chem Earth (B) 28(2):143-147

Gouirand I, Jury MR, Sing B (2012) An analysis of low- and highfrequency summer climate variability around the Caribbean Antilles. J Clim 25:3942-3952

Hamada JI, Yamanaka MD, Matsumoto J, Fukao S, Winarso PA, Sribimawati T (2002) Spatial and temporal variations of the rainy season over Indonesia and their link to ENSO. J Meteorol Soc Jpn $80: 285-310$

Hastenrath S (2002) The intertropical convergence zone of the eastern Pacific revisited. Int J Climatol 22:347-356

Henderson-Sellers A, Robinson PJ (1986) Contemporary climatology. Longman, New York

Hernández Ayala JJ (2019) Atmospheric teleconnections and their effects on the annual and seasonal rainfall climatology of Puerto Rico. Theor Appl Climatol. https://doi.org/10.1007/s00704-01902774-3

Herrera D, Ault T (2017) Insights from a new high-resolution drought atlas for the Caribbean spanning 1950 to 2016. J Clim 30(19):7801-7825. https://doi.org/10.1175/JCLI-D-16-0838.1

Herrera E, Magaña V, Caetano E (2015) Air-sea interactions and dynamical processes associated with the midsummer drought. Int J Climatol 35:1569-1578

Hidalgo HG, Durán-Quesada AM, Amador JA, Alfaro EJ (2015) The Caribbean low-level jet, the intertropical convergence zone and precipitation patterns in the intra-Americas sea: a proposed dynamical mechanism. Geografiska Annaler Ser A Phys Geogr 97:41-59

Hu ZZ, Kumar A, Huang B (2011) Persistent atmospheric and oceanic anomalies in the North Atlantic from summer 2009 to summer 
2010. J Clim 24(22):5812-5830. https://doi.org/10.1175/2011J CLI4213.1

Huang B, Thorne Peter W et al (2017) Extended reconstructed sea surface temperature version 5 (ERSSTv5), upgrades, validations, and intercomparisons. J Clim. https://doi.org/10.1175/ JCLI-D-16-0836.1

Hurrell JW, Kushnir Y, Visbeck M, Ottersen G (2003) An overview of the North Atlantic Oscillation. In: Hurrell JW, Kushnir Y, Otterson G, Visbeck MH (eds) The North Atlantic Oscillation, vol 134. AGU Geophysical Monograph, New York, pp 1-35

Ineson S, Scaife AA (2009) The role of the stratosphere in the European climate response to El Niño. Nat Geosci 2:32-36. https:// doi.org/10.1038/ngeo381

Jury M, Malmgren BA, Winter A (2007) Subregional precipitation climate of the Caribbean and relationships with ENSO and NAO. J Geophys Res 112:D16107

Kalnay E et al (1996) The NCEP/NCAR 40-year reanalysis project. Bull Am Meteorol Soc 77:437-472

King MP, Herceg-Bulić I, Kucharski F, Keenlyside N (2018) Interannual tropical Pacific sea surface temperature anomalies teleconnection to Northern Hemisphere atmosphere in November. Clim Dyn 50:1881-1899. https://doi.org/10.1007/s00382-017-3727-5

Kushnir Y (1994) Interdecadal variations in North Atlantic sea surface temperature and associated atmospheric conditions. J Clim $7: 141-157$

Kushnir Y, Robinson WA, Bladé I, Hall NMJ, Peng S, Sutton R (2002) Atmospheric GCM response to extratropical SST anomalies: synthesis and evaluation. J Clim 15:2233-2256

Kushnir Y, Robinson WA, Chang P, Robertson AW (2006) The physical basis for predicting Atlantic sector seasonal-to-interannual climate variability. J Clim 19:5949-5970

Madden R, Julian P (1971) Detection of a 40-50 day oscillation in zonal wind in the tropical Pacific. J Atmos Sci 28:702-708

Magaña V, Amador JA, Medina S (1999) The midsummer drought over Mexico and Central America. J Clim 12(6):1577-1588

Malmgren BA, Winter A, Chen D (1998) El Niño Southern oscillation and North Atlantic oscillation control of climate in Puerto Rico. J Clim 12(4):977-985

Marshall J, Kushnir Y, Battisti D, Chang P, Czaja A, Dickson R, Hurrell J, McCartney M, Saravanan R, Visbeck M (2001) North Atlantic climate variability, phenomena, impacts and mechanisms. Int J Climatol 21:1863-1898

Martin ER, Schumacher C (2011) Modulation of Caribbean precipitation by the Madden-Julian oscillation. J Clim 24:813-824

Martinez C, Goddard L, Kushnir Y, Ting M (2019) Seasonal climatology and dynamical mechanisms of rainfall in the Caribbean. Clim Dyn. https://doi.org/10.1007/s00382-019-04616-4

Mitchell T, Wallace JM (1992) The annual cycle in equatorial convection and sea surface temperature. J Clim 5:1140-1156

Moron V, Gouirand I (2003) Seasonal modulation of the ENSO relationship with sea level pressure anomalies over the North Atlantic in October-March 1873-1996. Int J Climatol 23:143-155. https://doi.org/10.1002/joc.868

Mote TL, Ramseyer CA, Miller PW (2017) The Saharan Air Layer as an early rainfall season suppressant in the eastern Caribbean: The 2015 Puerto Rico drought. J Geophys Res Atmos 122:10966-10982

Muñoz E, Busalacchi AJ, Nigam S, Ruiz-Barradas A (2008) Winter and summer structure of the Caribbean low-level jet. J Clim 21(6): $1260-1276$

National Oceanic and Atmospheric Administration (NOAA) the Climate Global Hazards (2005) State of the climate global hazards. National Climatic Data Center, July 2005. http://www.ncdc. noaa.gov/sotc/hazards/2005/jul. Accessed Jan 2019

Office of Disaster Preparedness and Emergency Management (ODPEM) (2010) 133 Communities impacted by Nicole.
Jamaica Observer, October 2, 2010. http://www.jamaicaobserver .com/news/133-communities-impacted-by-Nicole. Accessed Jan 2019

Poveda G, Mesa OJ (1997) Feedbacks between hydrological processes in tropical South America and large-scale ocean-atmospheric phenomena. J Clim 10:2690-2702

Reding PJ (1992) The Central American Cold Surge: an observational analysis of the deep southward penetration of North America Cold Fronts. M.Sc. Thesis, Department of Meteorology, Texas A\&M University

Rodriguez-Vera G, Romero-Centeno R, Castro CL, Castro VM (2019) Coupled interannual variability of wind and sea surface temperature in the Caribbean Sea and the Gulf of Mexico. J Clim 32:4263-4280. https://doi.org/10.1175/JCLI-D-18-0573.1

Ryu J-H, Hayhoe K (2013) Understanding the sources of Caribbean precipitation biases in CMIP3 and CMIP5 simulations. Clim Dyn 42(11-12):3233-3252

Sáenz F, Durán-Quesada AM (2015) A climatology of low level wind regimes over Central America using a weather type classification approach. Front Earth Sci 3:15

Scaife AA et al (2014) Skilful long range prediction of European and North American winters. Geophys Res Lett 41:2514-2519

Schultz DM, Bracken WE, Bosart LF (1998) Planetary- and synopticscale signatures associated with Central American Cold Surges. Mon Weather Rev 126:5-27

Seager R, Henderson N (2013) Diagnostic computation of moisture budgets in the ERA-interim reanalysis with reference to analysis of CMIP-archived atmospheric model data. J Clim 26:7876-7901

Seager R, Kushnir Y, Visbeck M, Naik N, Miller J et al (2000) Causes of Atlantic Ocean climate variability between 1958 and 1998. J Clim 13:2845-2862. https://doi.org/10.1175/15200442(2000)013\%3c2845:COAOCV\%3e2.0.CO;2

Servain J (1991) Simple climatic indices for the tropical Atlantic ocean and some applications. J Geophys Res 96:15137-15146. https:// doi.org/10.1029/91jc01046

Spence JM, Taylor MA, Chen AA (2004) The effect of concurrent seasurface temperature anomalies in the tropical Pacific and Atlantic on Caribbean rainfall. Int J Climatol 24:1531-1541. https://doi. org/10.1002/joc. 1068

Taylor MA, Enfield DB, Chen AA (2002) Influence of the tropical Atlantic versus the tropical Pacific on Caribbean rainfall. J Geophys Res 93:485-498

Taylor MA, Stephenson TS, Chen A, Stephenson K (2012) Climate change and the caribbean: review and response. Caribb Stud 40(2): 169-200

Torres-Valcárcel AR (2018) Teleconnections between ENSO and rainfall and drought in Puerto Rico. Int J Climatol 38:e1190-e1204. https://doi.org/10.1002/joc.5444

United Nations Office for the Coordination of Humanitarian 880 Affairs (OCHA) (2015) Drought in Central America in 2015 (as for October 6, 2015). https://redhum.org/documento/1205311. Accessed Jan 2019

United Nations Office for the Coordination of Humanitarian 880 Affairs (OCHA) (2016) Humanitarian bulletin: Haiti, June 2016, vol 62 , pp 5-6. https://www.humanitarianresponse.info/en/operations/ haiti/document/ocha-haiti-humanitarian-bulletin-62-june-2016fren. Accessed Jan 2019

Vaughan C, Dessai S (2014) Climate services for society: origins, institutional arrangements, and design elements for an evaluation framework. WIREs Clim Change 5:587-603. https://doi. org/10.1002/wcc. 290

Waliser DE, Gautier C (1993) A satellite-derived climatology of the ITCZ. J Clim 6:2162-2174

Wang C (2001) Atlantic climate variability and its associated atmospheric circulation cells. J Clim 15(13):1516-1536 
Wang C (2007) Variability of the Caribbean low-level jet and its relations to climate. Clim Dyn 29:411-422

Wang C, Lee S-K (2007) Atlantic warm pool, Caribbean low-level jet, and their potential impact on Atlantic hurricanes. Geophys Res Lett 34:L02703

Wang C, Enfield DB, Lee S-K, Landsea CW (2006) Influences of the Atlantic warm pool on Western Hemisphere summer rainfall and Atlantic hurricanes. J Clim 19:3011-3028

Wang C, Lee S-K, Enfield DB (2008) Climate response to anomalously large and small Atlantic warm pools during the summer. J Clim $21: 2437-2450$
Wang L, Ting M, Kushner PJ (2017) A robust empirical seasonal prediction of the winter NAO and surface climate. Sci Rep 7:279

Xie SP, Philander SGH (1994) A coupled ocean-atmosphere model of relevance to the ITCZ in the eastern Pacific. Tellus A 46(4):340-350

Publisher's Note Springer Nature remains neutral with regard to jurisdictional claims in published maps and institutional affiliations. 